\title{
An Improving failure Mode and Effect Analysis Method for Pallet Exchange Rack Risk Analysis
}

\section{Chuanxi Jin}

Chongqing University

Yan Ran ( $\sim$ ranyan@cqu.edu.cn )

Chongqing University https://orcid.org/0000-0002-7820-1094

Genbao Zhang

Chongqing University

\section{Research Article}

Keywords: Failure mode and effects analysis, Picture fuzzy sets, PFWA operator, PFWG operator, WASPAS

Posted Date: July 12th, 2021

DOI: https://doi.org/10.21203/rs.3.rs-330920/v1

License: (9) This work is licensed under a Creative Commons Attribution 4.0 International License. Read Full License 


\title{
An improving failure mode and effect analysis method for pallet exchange rack risk analysis
}

\author{
Chuanxi Jin ${ }^{\mathrm{a}}, \quad$ Yan $\operatorname{Ran}^{\mathrm{a}, *}, \quad$ Genbao Zhang ${ }^{\mathrm{a}, \mathrm{b}}$ \\ ${ }^{a}$ College of Mechanical Engineering and State Key Laboratory Mechanical Transmission, Chongqing University, Chongqing, 400044, China \\ ${ }^{\mathrm{b}}$ College of Mechanical Engineering, Chongqing University of Arts and Sciences, Chongqing, 402160, China \\ *Corresponding author: Yan Ran (ranyan@,cqu.edu.cn)
}

\begin{abstract}
In order to enhance quality and reliability of mechanical and electrical products, the methods of taking corresponding corrective measures to eliminate or alleviate product failure in advance have been widely concerned. Failure mode and effects analysis (FMEA) is a typical prevention reliability analysis method. However, there are some drawbacks in traditional FMEA method. To overcome these drawbacks, we propose a hybrid risk evaluation method, which combines picture fuzzy sets (PFSs), the PF-linear programming model (PF-LPM) method and the PF-weighted aggregated sum product assessment (PF-WASPAS) method. We adopt PFSs to evaluate risks of products. In order to overcome drawback of the traditional distance between PFSs, some new distance measures between PFSs based on the Dice similarity and the Jaccard similarity are proposed by us. The PFLPM method which considers the subjective weights of risk factors and calculates synthetical deviation with the Dice similaritybased distance is utilized to calculate the weights of risk factors. Moreover, the PFWA operator and the PFWG operator are used by us to fuse experts' evaluation information. Then, the PF-WASPAS method is utilized to rank failure modes. Finally, an illustrative example with respect to pallet exchange rack is introduced, and the rationality, effectiveness and applicability of the proposed method are verified by a discussion and comparison.
\end{abstract}

Keywords: Failure mode and effects analysis; Picture fuzzy sets; PFWA operator; PFWG operator; WASPAS

\section{Introduction}

As one of the six key quality characteristics (reliability, precision, precision life, maintainability, availability and precision stability) of CNC machine tools, reliability plays an important role in the quality improvement of CNC machine tools (Chen et al.). Reliability refers to the ability or possibility of a component, product or system to perform a specified function without failure under a certain period of time and certain conditions (Jin et al., 2020). In order to reduce the failure probability of products and improve reliability of products, many reliability improvement techniques have been proposed. For instance, failure mode and effects analysis (FMEA) (Boral et al., 2020a; Fang et al., 2020), fault tree analysis (FTA) (Hu et al., 2020a), event tree analysis (ETA) (Purba et al., 2020), hazard and operability studies (Marhavilas et al., 2020) and root cause analysis (RCA) (Velasquez, 2020). Among these methods, the FMEA is the most representative one, because it's main feature is taking actions to prevent the occurrence of failure in advance, rather than improving reliability through post-mortem testing. The implementation process of traditional FMEA method mainly includes six steps: identifying all potential failure modes of products according to failure data, analyzing the causes and effect of each failure mode based on experience, inviting experts to rate risks by utilizing crisp value, calculating risk priority numbers (RPNs) of each failure modes, ranking failure modes based on RPN values and taking corresponding corrective measures to eliminate or alleviate them (Li et al., 2019a; Lo et al., 2019; Liu et al., 2019a).

The ease of use of FMEA technique has let to the extension of its application in different fields, for example, risk assessment of maritime autonomous surface ships (Chang et al., 2021), failure analysis of diesel engine piston in transport utility vehicles (Deulgaonkar et al., 2021), risk evaluation and mitigation of sustainable road freight transport operation (Dadsena et al., 2019) and risk analysis of sequential processes in food industry (Rezaee et al., 2018) and so on. However, the traditional FMEA method does not have absolute advantages in the efficiency and effectiveness of risk evaluation. The reasons for this problem mainly include the following aspects (Zheng \& Tang, 2020; Boral et al., 2020b): (1) Rating risks by using crisp value, which ignores the hesitation and uncertainty of experts' evaluation information; (2) The weights of the three risk factors (S, O and D) are equal. It is not irrational, risk analysis cases differ, their weights should not be equal; (3) The mathematical form (i.e. multiplication) adopted for calculating the RPN value is irrational, because it is strongly sensitive to variations in criticality factor evaluations; (4) The same RPN value may indicate totally different risk implications. 
In order to overcome the above drawbacks and improve the effectiveness and efficiency of the traditional FMEA method, in this paper, we propose a new risk evaluation method based on the PF-LPM and the PF-WASPAS. Moreover, in order to extend the traditional distance measures between two PFSs, some new distance measures based on Dice similarity and Jaccard similarity are proposed by us. The proposed FMEA method mainly includes three parts: risk evaluation, calculating the weights of risk factors with PF-LPM and prioritizing risks with the PF-WASPAS method. In risk revaluation, taking the hesitation and uncertainty of experts' evaluation information into account, PFSs are utilized to rate risks. In calculating the weights of risk factors with PF-LPM, we consider the subjective weight of risk factors, and adopt the Dice similarity-based distance to calculate synthetical deviation. In order to obtain more consistent expert evaluation information, the PFWA operator and the PFWG operator are utilized to fuse experts' evaluation information. Finally, the weights of risk factors are calculated with PF-LPM. In prioritizing risks with the PF-WASPAS method, we adopt the PF-WASPAS method to rank failure modes.

Based on the above analysis, we can sum up the main motivation of this paper as follows: (1) In risk revaluation, under time pressure and limited knowledge and data, for some complex products or systems, experts may not be so focused, and different experts have different information processing capabilities. Therefore, the obtained experts' evaluation information may be uncertain and hesitant. However, the PFSs is of great help in solving this problem. Its parameters include positive degree of membership, neutral degree of membership, negative degree of membership and refusal degree of membership, which can express the hesitation and uncertainty of experts' evaluation information; (2) The traditional distance measure between PFSs fails to satisfy the axiomatic requirements of being PF distance measures, and may produce counterintuitive results in calculating the distance between different PFSs. Therefore, it is necessary for us to develop new distance measure between PFSs to solve this problem. The distance measure based on Dice similarity and Jaccard similarity can solve this problem well; (3) Because experts come from different fields and have different knowledge background, the experts' evaluation information may be inconsistent. In order to reach a consensus, we need to fuse the experts' evaluation information under PFSs environment. PFSs provide a parameterized family of aggregation operators such as the PFWA operator and the PFWG operator; (4) In the traditional FMEA method, the risk factors are equally weighted. However, for different risk evaluation cases, the weights of risk factors should not be equal. Moreover, the subjective weights of risk factors should be taken into account. The PF-LPM method can solve these problems well, which calculates synthetical deviation with the Dice similarity-based distance, and calculates the weights of risk factors by establishing a linear programming model; (5) The ranking mechanism of traditional FMEA method is irrational. However, The PF-WASPAS method is simple and direct, and can yield reasonable, acceptable and relatively accurate results in ranking failure modes.

Therefore, the major contributions of this paper are as follows: (1) Rating risks by using PFSs, which overcomes the drawback that the traditional FMEA method rates risks by crisp values and can not express the hesitation and uncertainty of experts' evaluation information; (2) Developing some new distance measures based on Dice similarity and Jaccard similarity, which extends traditional distance measure between PFSs, and overcomes the drawback that the traditional distance measure fails to satisfy the axiomatic requirements of being PF distance measures, and may produce counterintuitive results in calculating the distance between different PFSs; (3) Fusing experts' evaluation information by using the PFWA operator and the PFWG operator, which can make experts' evaluation information more consistent; (4) Calculating the weights of risk factors with the PF-LPM, which can overcome the drawback that the risk factors are weighted equally in the traditional FMEA method; (5) Ranking failure modes with the PF-WASPAS method. which can overcome the drawback that the ranking mechanism of the traditional FMEA method is irrational.

The organization of the rest paper is as follows. The literature review is synthesized in Section 2. In Section 3, some basic knowledge of the PFSs, the PFWA operator and the PFWG operator are briefly reviewed. Some new distance measures between PFSs are introduced in Section 4. Section 5 presents the proposed FMEA method, which includes risk evaluation, calculating the weights of risk factors with PF-LPM and prioritizing risks with the PF-WASPAS method. In Section 6, an illustrative example with respect to the pallet exchange rack is introduced. A discussion and comparison process is reported in Section 7 and conclusions are finally drawn in Section 8. 


\section{Literature review}

\subsection{The applications of PFSs}

The concept of PFSs was first proposed by Coung in 2014. It emerged from IFSs, but compared with IFSs, it is more powerful and suitable to deal with cases requiring human opinion involving more answers of types: yes, abstain, no and refusal (Xu et al., 2019). The ease of use of the PFSs has let to the extension of its application in different fields. For example, Luo et al. (Luo et al., 2020) adopted PFSs to indicate the subjective evaluation information in evaluating the thermal comfort of underground mines. In order to select the optimal electric vehicle charging station (EVCS) site from all the feasible sites in Beijing, the PFSs was utilized by Ju et al. (Ju et al., 2019) to rate EVCS sites. In the same vein, to select an optimal emergency alternative from four feasible emergency alternatives, Li et al. (Li et al., 2019b) adopted PFSs to rate emergency alternatives. Wang et al. (Wang et al., 2018a) adopted PFSs to determine whether the risks are prioritized to guarantee the quality, safety, and timely completion of the construction project. Zhang et al. (Zhang et al., 2020) adopted PFSs to rate suppliers in a practical supplier selection of a pump enterprise. In addition, the PFSs were also utilized in medical diagnosis and pattern recognition (Zeng et al., 2019), risk evaluation of flood disaster (Singh et al., 2018), multiple attribute decision making problems (Van Dinh \& Xuan Thao, 2018), building materials recognition (Wei \& Gao, 2018), and so forth. However, to the best of our knowledge, there is no study that rates risks by using PFSs in FMEA.

\subsection{Distance measures of PFSs}

In order to describe difference between two PFSs, many distance measure methods have been proposed. For instance, Dinh et al. (Van Dinh \& Xuan Thao, 2018) proposed some new distance measures between PFSs and adopted it in the Dinah pattern recognition problem. Some new PF distance measures were proposed by Dutta et al. (Dutta, 2018) to solve medical diagnosis problem. Singh et al. (Singh et al., 2018) used the distance measures between PFSs to determinate the flood disaster risk in the South region of India. Son et al. (Son, 2017) introduced some new distance measures between PFSs and adopted it in the clustering analysis. Khan et al. (Khan et al., 2020) proposed a Bi-parametric PF distance measure and demonstrated the application of the PF distance measure in the pattern recognition and medical diagnosis. Ganie et al. (Ganie \& Singh) proposed the concepts of the PF correlation measures and adopted it in pattern recognition, medical diagnosis, and clustering analysis. Liu et al. (Liu et al., 2019b) presented a picture fuzzy ordered weighted distance measure and adopted it in a practical application of investment alternatives selection. Duong et al. (Duong \& Thao, 2021) proposed a novel dissimilarity measure on PFSs and adopted it in multi-criteria decision making problem. Although these distance measure methods are widely used, these distance measures can not satisfy the axiomatic requirements of being distance measures between PFSs, and may produce counterintuitive results in calculating the distance between different PFSs. To this end, we propose some new distance measures between PFSs based on Dice similarity and Jaccard similarity. To the best of our knowledge, there is no study that does these works.

\subsection{Weighting methods and ranking methods}

In traditional FMEA method, the risk factors are equally weighted. It is irrational, because for different risk cases, the weights of risk factors should not be equal. In order to deal with this problem, many weighting methods have been proposed, For instance, in order to consider the experts' psychological behavior in the risk evaluation in FMEA approach, Wang et al. (Wang et al., 2018 b) adopt the prospect theory to calculate the weights of risk factors. A weighting method based on fuzzy analytical hierarchy process (FAHP) which has capability to incorporate inherent inconsistencies of a decision making process was developed by Boral et al. (Boral et al., 2020a) to calculate the weights of risk factors. Gul et al. (Gul et al., 2020) built a fuzzy best-worst method (FBWM) which determines the importance weights of criteria using two comparison matrices to weight risk factors. Mohsen et al. (Mohsen \& Fereshteh, 2017) utilized the concept of Shannon entropy to utilized deploy objective weights, and took the subjective weights of risk factors assigned by experts into account. A consensus-driven methodology was proposed by Zhang et al. (Zhang et al., 2019) to generate the weights of risk factors. Additionally, data envelopment analysis was also utilized to calculate the objective weights of risk factors. In this paper, we combine PFSs and LPM method to calculate the weights of risk factors, and take the subjective weights of risk factors into account. For LPM method, it is also widely used in different 
fields. For example, to highlight the overall difference among the performance values of alternatives, Yi et al. (Yi et al., 2019) adopted LPM method to calculate indicator weights. Under condition that the weights may be partially known or even completely unknown, Wu et al. (Wu et al., 2020) adopted LPM method to determine the weights of customer requirements. Li et al. (Li et al., 2019c) built the LPM method in dynamic situation to calculate indicator weights with the purpose of widening the overall difference of the development of the cities.

In traditional FMEA method, failure modes are ranked based on RPN values. According to Introduction, we can obtain that this ranking mechanism is irrational. To this end, Luo et al. (Luo \& Liang, 2019) proposed the multi-attributive border approximation area comparison (MABAC) method based on likelihood to rank roadway support schemes. In (Nie et al., 2018), an alternative FMEA model which combines best-worst, maximizing derivation and COPRAS methods was utilized to evaluate the risk of a supercritical water gasification system. Chen et al. (Chen \& Deng, 2018) proposed a new FMEA model which combined grey relational projection (GRP) method and dempster-shafer theory method to evaluate the risks of aircraft turbine rotor blades. In order to improve the capabilities of the traditional FMEA method, Zhao et al. (Zhao et al., 2016) proposed a modified MULTIMOORA approach based on interval-valued intuitionistic fuzzy sets and continuous weighted entropy. Shin et al. adopted the DEMATEL approach to identify and prioritize failure modes of a software development process. Wang et al. (Wang et al., 2018b) proposed a risk evaluation based on prospect theory and Choquet integral, which considered decision maker's psychological behavior and risk factors' interaction relationships simultaneously. Hu et al. (Hu et al., 2020b) proposed an FMEA model based on multi-granularity linguistic terms and the dempster-shafer evidence theory, An integrated robust DEAFMEA approach was proposed by Yousefi et al. (Yousefi et al., 2018) to evaluate and prioritize safety and environment risks, which considered two extra risk factors: cost and duration of treatment. In this paper, the PF-WASPAS method is utilized by us to rank failure modes, which combine PFSs and the WASPAS method. For the WASPAS method, Mardani et al. (Mardani et al., 2020) adopted the WASPAS method to rank digital technologies (DTs) under hesitant fuzzy sets. A hybrid fuzzy multi-criteria decision making method based on level based weight assessment-WASPAS-Heronian (LBWA-WASPAS-H) model was proposed by Pamucar et al. (Pamucar et al., 2020) to select ground access mode. To the best of our knowledge, there is no study that weights risk factors with the PF-LPM method and ranks failure modes with the PF-WASPAS method.

\section{Preliminaries}

In this section, some basic knowledge about PFSs that will be utilized in the subsequent research are briefly reviewed.

\subsection{Picture fuzzy sets}

As an extension of FSs and IFSs, PFSs can express the evaluation information more accurately and comprehensively than FSs and IFSs when experts face opinions involving four types of answers. It is defined as following.

Definition 1. (Tian et al., 2019) A picture fuzzy set $T$ over the universe of discourse $X$ is interpreted as $T=\left\{\left\langle a_{T}(x), b_{T}(x), c_{T}(x)\right\rangle \mid x \in X\right\}$, where positive degree of membership $a_{T}(x): X \rightarrow[0,1]$, neutral degree of membership $b_{T}(x): X \rightarrow[0,1]$ and negative degree of membership $c_{T}(x): X \rightarrow[0,1]$ in a fuzzy set $T$ such that for every $x \in X$. Also, the degree of refusal is defined for $x$ as $\pi_{T}(x)=1-a_{T}(x)-b_{T}(x)-c_{T}(x)$. In particular, when only one element exists in $X$, the PFS can be degraded to a picture fuzzy number (PFN). For the sake of convenience, we call $T=(a, b, c)$ a PFN.

Then, some operational rules with respect to PFSs are introduced.

Definition 2. (Tian et al., 2019) Let $T_{1}=\left(a_{1}, b_{1}, c_{1}\right), T_{2}=\left(a_{2}, b_{2}, c_{2}\right)$ and $T=(a, b, c)$ be three PFNs, their operational rules contain

(1) $\bar{T}=(c, b, a)$,

(2) $T_{1} \oplus T_{2}=\left(a_{1}+a_{2}-a_{1} a_{2}, b_{1} b_{2}, c_{1} c_{2}\right)$,

(3) $T_{1} \otimes T_{2}=\left(a_{1} a_{2}, b_{1}+b_{2}-b_{1} b_{2}, c_{1}+c_{2}-c_{1} c_{2}\right)$,

(4) $T^{\lambda}=\left(a^{\lambda}, 1-(1-b)^{\lambda}, 1-(1-c)^{\lambda}\right)$,

(5) $\lambda T=\left(1-(1-a)^{\lambda}, b^{\lambda}, c^{\lambda}\right)$. 
In order to compare two PFNs, Wang et al. introduced the concepts of the score function and the accuracy function of a PFN. Definition 3. (Jana et al., 2019) For a PFN $T=(a, b, c)$, its score function and accuracy function can be defined as

$$
\begin{aligned}
& S(T)=a-c \\
& A(T)=a+b+c
\end{aligned}
$$

Definition 4. (Jana et al., 2019) Suppose $T_{1}=\left(a_{1}, b_{1}, c_{1}\right)$ and $T_{2}=\left(a_{2}, b_{2}, c_{2}\right)$ are two arbitrary PFNs. The preference relations between them can be determined by the following principles:

(1) When $S\left(T_{1}\right)<S\left(T_{2}\right)$, then $T_{1}$ p $T_{2}$;

(2) When $S\left(T_{1}\right)=S\left(T_{2}\right)$, if $A\left(T_{1}\right)<A\left(T_{2}\right)$, then $T_{1} \mathrm{p} T_{2}$, if $A\left(T_{1}\right)=A\left(T_{2}\right)$, then $T_{1}: T_{2}$.

To measure the deviation or difference between two PFNs, the normalized Hamming distance of PFSs was proposed by Zhang et al (Zhang et al., 2020).

Definition 5. Suppose $T_{1}=\left(a_{1}, b_{1}, c_{1}\right)$ and $T_{2}=\left(a_{2}, b_{2}, c_{2}\right)$ are two arbitrary PFNs, then the normalized Hamming distance between $T_{1}$ and $T_{2}$ can be obtained as follows:

$$
d\left(T_{1}, T_{2}\right)=\frac{1}{3}\left(\left|a_{1}-a_{2}\right|+\left|b_{1}-b_{2}\right|+\left|c_{1}-c_{2}\right|\right)
$$

\subsection{PFWA operator and PFWG operator}

To fuse experts' evaluation information, the picture fuzzy weighted averaging (PFWA) operator and the picture fuzzy weighted geometric mean (PFWG) operator of PFSs are defined.

Definition 6. (Wei, 2017) Let $T_{j}=\left(a_{j}, b_{j} c_{j}\right)(j=1,2, \cdots, n)$ be a collection of PFNs. The PFWA operator is a mapping $P^{n} \rightarrow P$ such that

$$
\operatorname{PFWA}\left(T_{1}, T_{2}, \mathrm{~L}, T_{n}\right)=\bigoplus_{j=1}^{n}\left(\omega_{j} T_{j}\right)=\left(1-\prod_{j=1}^{n}\left(1-a_{j}\right)^{\omega_{j}}, \prod_{j=1}^{n}\left(b_{j}\right)^{\omega_{j}}, \prod_{j=1}^{n}\left(c_{j}\right)^{\omega_{j}}\right)
$$

where $\omega=\left(\omega_{1}, \omega_{2}, \cdots, \omega_{n}\right)^{T}$ is the weight vector of $T_{j}(j=1,2, \cdots, n)$, it can be calculated by a weighted generation method based on the normal distribution (Chen et al., 2020), and $\omega_{j}>0, \quad \sum_{j=1}^{n} \omega_{j}=1$.

Definition 7. (Wei, 2017) Let $T_{j}=\left(a_{j}, b_{j} c_{j}\right)(j=1,2, \cdots, n)$ be a collection of PFNs. The PFWG operator is a mapping $P^{n} \rightarrow P$ such that

$$
P F W G\left(T_{1}, T_{2}, \mathrm{~L}, T_{n}\right)=\bigotimes_{j=1}^{n}\left(T_{j}\right)^{\omega_{j}}=\left(\prod_{j=1}^{n}\left(a_{j}\right)^{\omega_{j}}, 1-\prod_{j=1}^{n}\left(1-b_{j}\right)^{\omega_{j}}, 1-\prod_{j=1}^{n}\left(1-c_{j}\right)^{\omega_{j}}\right)
$$

where $\omega=\left(\omega_{1}, \omega_{2}, \cdots, \omega_{n}\right)^{T}$ is the weight vector of $T_{j}(j=1,2, \cdots, n)$, it can be calculated by a weighted generation method based on the normal distribution (Chen et al., 2020), and $\omega_{j}>0, \quad \sum_{j=1}^{n} \omega_{j}=1$.

\section{New distance measures between PFSs}

In this section, some new distance measures between PFSs based on the Dice similarity and Jaccard similarity are proposed to overcome drawback that information loss may be caused in traditional distance measure.

\subsection{The Dice similarity-based distance measure}

The concept of the Dice similarity was first proposed by Dice in 1945 (Dice, 1945), it is defined as follows.

Definition 7. Let $T_{1}=\left\langle a_{1}\left(x_{i}\right), b_{1}\left(x_{i}\right), c_{1}\left(x_{i}\right)\right\rangle$ and $T_{2}=\left\langle a_{2}\left(x_{i}\right), b_{2}\left(x_{i}\right), c_{2}\left(x_{i}\right)\right\rangle$ be two PFSs in a given finite set $X=\left\{x_{1}, x_{2}, \mathrm{~L} x_{n}\right\}$. Then, the Dice similarity between $T_{1}$ and $T_{2}$ can be obtained as follows: 


$$
S_{D}\left(T_{1}, T_{2}\right)=\frac{1}{n} \sum_{i=1}^{n}\left(\frac{2\left(a_{1}\left(x_{i}\right) a_{2}\left(x_{i}\right)+b_{1}\left(x_{i}\right) b_{2}\left(x_{i}\right)+c_{1}\left(x_{i}\right) c_{2}\left(x_{i}\right)\right)}{a_{1}^{2}\left(x_{i}\right)+b_{1}^{2}\left(x_{i}\right)+c_{1}^{2}\left(x_{i}\right)+a_{2}^{2}\left(x_{i}\right)+b_{2}^{2}\left(x_{i}\right)+c_{2}^{2}\left(x_{i}\right)}\right)
$$

Then, the Dice similarity-based distance measure between PFSs is proposed by us to extend traditional distance measure, it is defined as follows.

Definition 8. Let $T_{1}=\left\langle a_{1}\left(x_{i}\right), b_{1}\left(x_{i}\right), c_{1}\left(x_{i}\right)\right\rangle$ and $T_{2}=\left\langle a_{2}\left(x_{i}\right), b_{2}\left(x_{i}\right), c_{2}\left(x_{i}\right)\right\rangle$ be two PFSs in a given finite set $X=\left\{x_{1}, x_{2}, \mathrm{~L} x_{n}\right\}$. Then, the Dice similarity-based distance measure between $T_{1}$ and $T_{2}$ can be obtained as follows:

$$
d_{D S}\left(T_{1}, T_{2}\right)=1-S_{D}\left(T_{1}, T_{2}\right)=1-\frac{1}{n} \sum_{i=1}^{n}\left(\frac{2\left(a_{1}\left(x_{i}\right) a_{2}\left(x_{i}\right)+b_{1}\left(x_{i}\right) b_{2}\left(x_{i}\right)+c_{1}\left(x_{i}\right) c_{2}\left(x_{i}\right)\right)}{a_{1}^{2}\left(x_{i}\right)+b_{1}^{2}\left(x_{i}\right)+c_{1}^{2}\left(x_{i}\right)+a_{2}^{2}\left(x_{i}\right)+b_{2}^{2}\left(x_{i}\right)+c_{2}^{2}\left(x_{i}\right)}\right)
$$

Property 1. Based on the above definition, we can obtain that:

(1) $0 \leq d_{D S}\left(T_{1}, T_{2}\right)<1$;

(2) $d_{D S}\left(T_{1}, T_{2}\right)=d_{D S}\left(T_{2}, T_{1}\right)$;

(3) $d_{D S}\left(T_{1}, T_{2}\right)=0$ if and only if $T_{1}=T_{2}$.

\section{Proof}

(1) According to the definition of PFSs, $a(x) \in[0,1], b(x) \in[0,1]$ and $c(x) \in[0,1]$, then, $d_{D S}\left(T_{1}, T_{2}\right) \geq 0$. Because $a^{2}+b^{2} \geq 2 a b$, we have $2\left(a_{1}\left(x_{i}\right) a_{2}\left(x_{i}\right)+b_{1}\left(x_{i}\right) b_{2}\left(x_{i}\right)+c_{1}\left(x_{i}\right) c_{2}\left(x_{i}\right)\right) \leq a_{1}^{2}\left(x_{i}\right)+b_{1}^{2}\left(x_{i}\right)+c_{1}^{2}\left(x_{i}\right)+a_{2}^{2}\left(x_{i}\right)+b_{2}^{2}\left(x_{i}\right)+c_{2}^{2}\left(x_{i}\right)$, then, $0 \leq d_{D S}\left(T_{1}, T_{2}\right)<1$.

(2) According to the definition, we can obtain that the Dice similarity-based distance measure satisfies the second condition.

(3) If $T_{1}=T_{2}$, then $a_{1}\left(x_{i}\right)=a_{2}\left(x_{i}\right), b_{1}\left(x_{i}\right)=b_{2}\left(x_{i}\right)$ and $c_{1}\left(x_{i}\right)=c_{2}\left(x_{i}\right)$. Therefore, we can obtain that $d_{D S}\left(T_{1}, T_{2}\right)=0$. If $d_{D S}\left(T_{1}, T_{2}\right)=0$, there is $2\left(a_{1}\left(x_{i}\right) a_{2}\left(x_{i}\right)+b_{1}\left(x_{i}\right) b_{2}\left(x_{i}\right)+c_{1}\left(x_{i}\right) c_{2}\left(x_{i}\right)\right)=a_{1}^{2}\left(x_{i}\right)+b_{1}^{2}\left(x_{i}\right)+c_{1}^{2}\left(x_{i}\right)+a_{2}^{2}\left(x_{i}\right)+b_{2}^{2}\left(x_{i}\right)+c_{2}^{2}\left(x_{i}\right)$. then, $\left(a_{1}\left(x_{i}\right)-a_{2}\left(x_{i}\right)\right)^{2}+\left(b_{1}\left(x_{i}\right)-b_{2}\left(x_{i}\right)\right)^{2}+\left(c_{1}\left(x_{i}\right)-c_{2}\left(x_{i}\right)\right)^{2}=0$. Thus, $a_{1}\left(x_{i}\right)=a_{2}\left(x_{i}\right), b_{1}\left(x_{i}\right)=b_{2}\left(x_{i}\right)$ and $c_{1}\left(x_{i}\right)=c_{2}\left(x_{i}\right)$, that is, $T_{1}=T_{2}$. This completes the proof.

Because the weights of PFNs have great influence on the distance measure between PFNs, we proposed the concept of the Dice similarity-based weighted distance measure, it is defined as follows.

Definition 9. Let $T_{1}=\left\langle a_{1}\left(x_{i}\right), b_{1}\left(x_{i}\right), c_{1}\left(x_{i}\right)\right\rangle$ and $T_{2}=\left\langle a_{2}\left(x_{i}\right), b_{2}\left(x_{i}\right), c_{2}\left(x_{i}\right)\right\rangle$ be two PFSs in a given finite set $X=\left\{x_{1}, x_{2}, \mathrm{~L} x_{n}\right\}$. Then, the Dice similarity-based weighted distance measure between $T_{1}$ and $T_{2}$ can be obtained as follows:

$$
d_{D S}^{\omega}\left(T_{1}, T_{2}\right)=1-S_{D}\left(T_{1}, T_{2}\right)=1-\frac{1}{n} \sum_{i=1}^{n} \omega_{i}\left(\frac{2\left(a_{1}\left(x_{i}\right) a_{2}\left(x_{i}\right)+b_{1}\left(x_{i}\right) b_{2}\left(x_{i}\right)+c_{1}\left(x_{i}\right) c_{2}\left(x_{i}\right)\right)}{a_{1}^{2}\left(x_{i}\right)+b_{1}^{2}\left(x_{i}\right)+c_{1}^{2}\left(x_{i}\right)+a_{2}^{2}\left(x_{i}\right)+b_{2}^{2}\left(x_{i}\right)+c_{2}^{2}\left(x_{i}\right)}\right)
$$

In the same vein, the Dice similarity-based weighted distance measure between PFSs also satisfies: $(1) \quad 0 \leq d_{D S}^{\omega}\left(T_{1}, T_{2}\right)<1$;

(2) $d_{D S}^{\omega}\left(T_{1}, T_{2}\right)=d_{D S}^{\omega}\left(T_{2}, T_{1}\right) ;(3) d_{D S}^{\omega}\left(T_{1}, T_{2}\right)=0$ if and only if $T_{1}=T_{2}$.

\subsection{The Jaccard similarity-based distance measures}

The concept of the Jaccard similarity was first proposed by Jaccard in 1901 (Jaccard, 1901), it is defined as follows.

Definition 10. Let $T_{1}=\left\langle a_{1}\left(x_{i}\right), b_{1}\left(x_{i}\right), c_{1}\left(x_{i}\right)\right\rangle$ and $T_{2}=\left\langle a_{2}\left(x_{i}\right), b_{2}\left(x_{i}\right), c_{2}\left(x_{i}\right)\right\rangle$ be two PFSs in a given finite set $X=\left\{x_{1}, x_{2}, \mathrm{~L} x_{n}\right\}$. Then, the Jaccard similarity between $T_{1}$ and $T_{2}$ can be obtained as follows: 


$$
S_{J}\left(T_{1}, T_{2}\right)=\frac{1}{n} \sum_{i=1}^{n}\left(\frac{a_{1}\left(x_{i}\right) a_{2}\left(x_{i}\right)+b_{1}\left(x_{i}\right) b_{2}\left(x_{i}\right)+c_{1}\left(x_{i}\right) c_{2}\left(x_{i}\right)}{\left(a_{1}^{2}\left(x_{i}\right)+b_{1}^{2}\left(x_{i}\right)+c_{1}^{2}\left(x_{i}\right)+a_{2}^{2}\left(x_{i}\right)+b_{2}^{2}\left(x_{i}\right)+c_{2}^{2}\left(x_{i}\right)\right)-a_{1}\left(x_{i}\right) a_{2}\left(x_{i}\right)+b_{1}\left(x_{i}\right) b_{2}\left(x_{i}\right)+c_{1}\left(x_{i}\right) c_{2}\left(x_{i}\right)}\right)
$$

Then, the Jaccard similarity-based distance measure between PFSs is proposed by us to extend traditional distance measure, it is defined as follows.

Definition 11. Let $T_{1}=\left\langle a_{1}\left(x_{i}\right), b_{1}\left(x_{i}\right), c_{1}\left(x_{i}\right)\right\rangle$ and $T_{2}=\left\langle a_{2}\left(x_{i}\right), b_{2}\left(x_{i}\right), c_{2}\left(x_{i}\right)\right\rangle$ be two PFSs in a given finite set $X=\left\{x_{1}, x_{2}, \mathrm{~L} x_{n}\right\}$.

Then, the Jaccard similarity-based distance measure between $T_{1}$ and $T_{2}$ can be obtained as follows:

$$
d_{J S}\left(T_{1}, T_{2}\right)=1-S_{J}\left(T_{1}, T_{2}\right)=1-\frac{1}{n} \sum_{i=1}^{n}\left(\begin{array}{l}
\frac{a_{1}\left(x_{i}\right) a_{2}\left(x_{i}\right)+b_{1}\left(x_{i}\right) b_{2}\left(x_{i}\right)+c_{1}\left(x_{i}\right) c_{2}\left(x_{i}\right)}{\left(a_{1}^{2}\left(x_{i}\right)+b_{1}^{2}\left(x_{i}\right)+c_{1}^{2}\left(x_{i}\right)+a_{2}^{2}\left(x_{i}\right)+b_{2}^{2}\left(x_{i}\right)+c_{2}^{2}\left(x_{i}\right)\right)} \\
-a_{1}\left(x_{i}\right) a_{2}\left(x_{i}\right)+b_{1}\left(x_{i}\right) b_{2}\left(x_{i}\right)+c_{1}\left(x_{i}\right) c_{2}\left(x_{i}\right)
\end{array}\right)
$$

Property 2. Similarly, the Jaccard similarity-based distance measure between PFSs satisfies:

(1) $0 \leq d_{J S}\left(T_{1}, T_{2}\right)<1$;

(2) $d_{J S}\left(T_{1}, T_{2}\right)=d_{J S}\left(T_{2}, T_{1}\right)$;

(3) $d_{J S}\left(T_{1}, T_{2}\right)=0$ if and only if $T_{1}=T_{2}$.

\section{Proof}

(1) Since $a^{2}+b^{2} \geq 2 a b$, we can obtain that

$$
\begin{aligned}
& 2\left(a_{1}\left(x_{i}\right) a_{2}\left(x_{i}\right)+b_{1}\left(x_{i}\right) b_{2}\left(x_{i}\right)+c_{1}\left(x_{i}\right) c_{2}\left(x_{i}\right)\right) \leq a_{1}^{2}\left(x_{i}\right)+b_{1}^{2}\left(x_{i}\right)+c_{1}^{2}\left(x_{i}\right)+a_{2}^{2}\left(x_{i}\right)+b_{2}^{2}\left(x_{i}\right)+c_{2}^{2}\left(x_{i}\right) \\
& \Rightarrow a_{1}\left(x_{i}\right) a_{2}\left(x_{i}\right)+b_{1}\left(x_{i}\right) b_{2}\left(x_{i}\right)+c_{1}\left(x_{i}\right) c_{2}\left(x_{i}\right) \leq\left(a_{1}^{2}\left(x_{i}\right)+b_{1}^{2}\left(x_{i}\right)+c_{1}^{2}\left(x_{i}\right)+a_{2}^{2}\left(x_{i}\right)+b_{2}^{2}\left(x_{i}\right)+c_{2}^{2}\left(x_{i}\right)\right)- \\
& a_{1}\left(x_{i}\right) a_{2}\left(x_{i}\right)+b_{1}\left(x_{i}\right) b_{2}\left(x_{i}\right)+c_{1}\left(x_{i}\right) c_{2}\left(x_{i}\right) \\
& \Rightarrow \frac{a_{1}\left(x_{i}\right) a_{2}\left(x_{i}\right)+b_{1}\left(x_{i}\right) b_{2}\left(x_{i}\right)+c_{1}\left(x_{i}\right) c_{2}\left(x_{i}\right)}{\left(a_{1}^{2}\left(x_{i}\right)+b_{1}^{2}\left(x_{i}\right)+c_{1}^{2}\left(x_{i}\right)+a_{2}^{2}\left(x_{i}\right)+b_{2}^{2}\left(x_{i}\right)+c_{2}^{2}\left(x_{i}\right)\right)} \leq 1 \\
& \quad-a_{1}\left(x_{i}\right) a_{2}\left(x_{i}\right)+b_{1}\left(x_{i}\right) b_{2}\left(x_{i}\right)+c_{1}\left(x_{i}\right) c_{2}\left(x_{i}\right)
\end{aligned}
$$

Thus, $0 \leq d_{J S}\left(T_{1}, T_{2}\right)<1$.

(2) It is obvious that $d_{J S}\left(T_{1}, T_{2}\right)=d_{J S}\left(T_{2}, T_{1}\right)$.

(3) If $T_{1}=T_{2}$, then $d_{D S}\left(T_{1}, T_{2}\right)=0$. If $d_{D S}\left(T_{1}, T_{2}\right)=0$, we can obtain that

$$
\begin{aligned}
& \frac{a_{1}\left(x_{i}\right) a_{2}\left(x_{i}\right)+b_{1}\left(x_{i}\right) b_{2}\left(x_{i}\right)+c_{1}\left(x_{i}\right) c_{2}\left(x_{i}\right)}{\left(a_{1}^{2}\left(x_{i}\right)+b_{1}^{2}\left(x_{i}\right)+c_{1}^{2}\left(x_{i}\right)+a_{2}^{2}\left(x_{i}\right)+b_{2}^{2}\left(x_{i}\right)+c_{2}^{2}\left(x_{i}\right)\right)}=1 \\
& -a_{1}\left(x_{i}\right) a_{2}\left(x_{i}\right)+b_{1}\left(x_{i}\right) b_{2}\left(x_{i}\right)+c_{1}\left(x_{i}\right) c_{2}\left(x_{i}\right) \\
& \Rightarrow a_{1}\left(x_{i}\right) a_{2}\left(x_{i}\right)+b_{1}\left(x_{i}\right) b_{2}\left(x_{i}\right)+c_{1}\left(x_{i}\right) c_{2}\left(x_{i}\right)=\left(a_{1}^{2}\left(x_{i}\right)+b_{1}^{2}\left(x_{i}\right)+c_{1}^{2}\left(x_{i}\right)+a_{2}^{2}\left(x_{i}\right)+b_{2}^{2}\left(x_{i}\right)+c_{2}^{2}\left(x_{i}\right)\right)- \\
& a_{1}\left(x_{i}\right) a_{2}\left(x_{i}\right)+b_{1}\left(x_{i}\right) b_{2}\left(x_{i}\right)+c_{1}\left(x_{i}\right) c_{2}\left(x_{i}\right) \\
& \Rightarrow\left(a_{1}\left(x_{i}\right)-a_{2}\left(x_{i}\right)\right)^{2}+\left(b_{1}\left(x_{i}\right)-b_{2}\left(x_{i}\right)\right)^{2}+\left(c_{1}\left(x_{i}\right)-c_{2}\left(x_{i}\right)\right)^{2}=0
\end{aligned}
$$

Thus, $T_{1}=T_{2}$. This completes the proof.

Then, we introduce the weights of PFSs into the Jaccard similarity-based distance measure, and define the concept of the Jaccard similarity-based weighted distance measure between PFSs.

Definition 12. Let $T_{1}=\left\langle a_{1}\left(x_{i}\right), b_{1}\left(x_{i}\right), c_{1}\left(x_{i}\right)\right\rangle$ and $T_{2}=\left\langle a_{2}\left(x_{i}\right), b_{2}\left(x_{i}\right), c_{2}\left(x_{i}\right)\right\rangle$ be two PFSs in a given finite set $X=\left\{x_{1}, x_{2}, \mathrm{~L} x_{n}\right\}$.

Then, the Jaccard similarity-based weighted distance measure between $T_{1}$ and $T_{2}$ can be obtained as follows:

$$
d_{J s}^{\omega}\left(T_{1}, T_{2}\right)=1-S_{J}\left(T_{1}, T_{2}\right)=1-\frac{1}{n} \sum_{i=1}^{n} \omega_{i}\left(\begin{array}{l}
\frac{a_{1}\left(x_{i}\right) a_{2}\left(x_{i}\right)+b_{1}\left(x_{i}\right) b_{2}\left(x_{i}\right)+c_{1}\left(x_{i}\right) c_{2}\left(x_{i}\right)}{\left(a_{1}^{2}\left(x_{i}\right)+b_{1}^{2}\left(x_{i}\right)+c_{1}^{2}\left(x_{i}\right)+a_{2}^{2}\left(x_{i}\right)+b_{2}^{2}\left(x_{i}\right)+c_{2}^{2}\left(x_{i}\right)\right)} \\
-a_{1}\left(x_{i}\right) a_{2}\left(x_{i}\right)+b_{1}\left(x_{i}\right) b_{2}\left(x_{i}\right)+c_{1}\left(x_{i}\right) c_{2}\left(x_{i}\right)
\end{array}\right)
$$


Similarly, the Jaccard similarity-based weighted distance measure between PFSs also satisfies: $(1) \quad 0 \leq d_{J S}^{\omega}\left(T_{1}, T_{2}\right)<1 ;(2)$

$d_{J S}^{\omega}\left(T_{1}, T_{2}\right)=d_{J S}^{\omega}\left(T_{2}, T_{1}\right) ;(3) d_{J S}^{\omega}\left(T_{1}, T_{2}\right)=0$ if and only if $T_{1}=T_{2}$.

\section{The proposed FMEA method}

In this paper, we proposed a new risk evaluation method based on the PF-LPM and the PF-WASPAS. The concrete steps of the proposed FMEA method are shown in Fig. 1. According to Fig. 1, we can obtain that the proposed FMEA method mainly includes three steps: risk evaluation, calculating the weights of risk factors with the PF-LPM and prioritizing risks with PFWASPAS method. In risk evaluation, PFSs is utilized to evaluate risks. In calculating the weights of risk factors with the PFLPM, the proposed Dice similarity-based distance of PFSs is used to calculate synthetical deviation. The PFWA operator and PFWG operator are utilized to fuse experts' evaluation information, and the weights of risk factors are calculated with PF-LPM method. In prioritizing risks with the PF-WASPAS method, the failure modes are ranked by using the PF-WASPAS method. Next, we will illustrate each step of the proposed FMEA method in detail according to Fig .1.

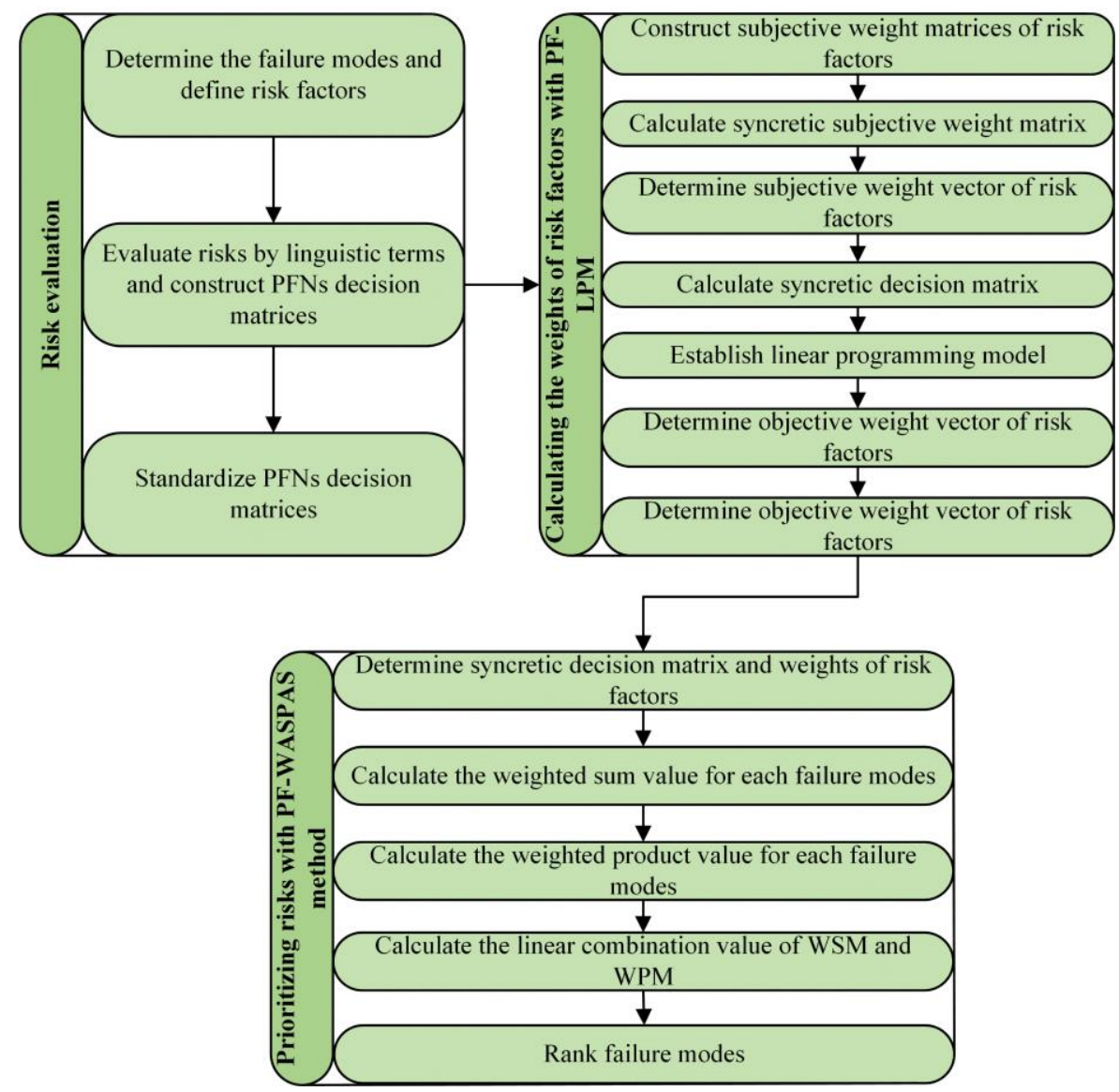

Fig. 1. The framework of the proposed FMEA method

\subsection{Risk evaluation}

In traditional FMEA method, we determine all potential failure modes of products based on experts' experience and evaluate risks by using crisp values. However, on one hand, because experts' evaluation information is subjective, some key failure modes may be lost in risk evaluation process. To solve this problem, the failure tree of product is constructed to determine potential failure modes based on failure data collected. On other hand, in real life, it is impossible to describe the exact risk level with specific numbers owing to time pressure and limited knowledge or data, and various hesitation and uncertainty will appear in the experts' subjective evaluation. In this case, given that PFSs have an inherent superiority in solving this problem, we can adopt PFSs to rate risks. The concrete risk evaluation process includes the following three steps. 
Step 1. Determine the failure modes and define risk factors.

Before conducting a risk evaluation, it is necessary for us to form a technical team and an expert team. The technical team is composed of fifteen basic technical staffs in the company, who come from five different departments: design, manufacturing, technical service, business and production management, each with 3-5 years of experience in CNC machine tool manufacturing industry. The expert team is composed of seven senior technical staffs in the company, who come from five different team too, but each with more than 15 years of experience.

In order to determine potential failure modes of product, we invite staffs in the technical team to collect product data, which includes design drawings, design specification and fault data, and to establish failure tree based on product data collected. Then, based on failure tree constructed, we invite $l$ experts $e_{k}(k=1,2, \mathrm{~L} l), l \in[0,7]$ to determine potential failure modes of product that cause system failure, denoted by $F M=\left\{F M_{1}, F M_{2} \mathrm{~L} F M_{m}\right\}$, where $F M_{i}(i=1,2, \mathrm{~L} m)$ indicates the $i$ th failure mode. Based on traditional RPN method, we can obtain that risk factors include $\mathrm{S}, \mathrm{O}$ and $\mathrm{D}, R F=\left\{R F_{1}, R F_{2}, \mathrm{~L} R F_{p}\right\}=\{S, O, D\}, p=3$, where $R F_{y}(y=1,2, \mathrm{~L} p)$ means the $y$ th risk factor.

Step 2. Evaluate risks by linguistic terms and construct PFNs decision matrices.

In the real life, due to time pressure and lack of knowledge or data, there may be hesitation or uncertainty about experts' evaluation information. In this paper, we define that seven grades of experts' evaluation information for rating failure modes are expressed as linguistic terms. Linguistic terms and corresponding picture fuzzy numbers are shown in Table 1. In order to rate risks, three of seven experts in expert team are invited to provide their assessments over failure modes using linguistic terms to establish linguistic terms decision matrices, denoted by $\boldsymbol{T}^{k}=\left(T_{i y}^{k}\right)_{m \times p}, k=1,2, \mathrm{~L} l ; i=1,2, \mathrm{~L} m ; y=1,2, \mathrm{~L} p$, where $L_{i y}^{k}$ indicates a linguistic term information of failure mode $F M_{i}$ with respect to risk factor $R F_{j}$ given by expert $e_{k}$. After converting linguistic terms information into corresponding PFNs based on Table 1, the PF evaluation information of the $i$ th failure mode with respect to the $j$ th risk factor provided by expert $e_{k}$ can be denoted as $x_{i y}^{k}=\left(a_{i y}, b_{i y}, c_{i y}\right), k=1,2, \mathrm{~L} l ; i=1,2, \mathrm{~L} m ; y=1,2, \mathrm{~L} p$, and PFNs decision matrices can be established as $X^{k}=\left(X_{i y}^{k}\right)_{m \times p}$.

Table 1 Linguistic terms and corresponding picture fuzzy numbers

\begin{tabular}{ll}
\hline Linguistic terms & Picture fuzzy numbers \\
\hline Very very low (VVL) & $(0,0,1)$ \\
Very low (VL) & $(0,0.05,0.9)$ \\
Low (L) & $(0.2,0.45,0.25)$ \\
Fair (F) & $(0.45,0.4,0.1)$ \\
High (H) & $(0.8,0.1,0.05)$ \\
Very High (VH) & $(0.9,0.05,0)$ \\
Very very high (VVH) & $(1,0,0)$ \\
\hline
\end{tabular}

Step 3. Standardize PFNs decision matrices.

In order to make experts' evaluation information more realistic, we need to standardize PFNs decision matrices as follows:

$$
X_{i y}^{k}=\left(a_{i y}, b_{i y}, c_{i y}\right)=\left\{\begin{array}{lc}
x_{i y}^{k} & \mathrm{~S} \text { and } \mathrm{O} \\
\left(x_{i y}^{k}\right)^{c} & \mathrm{D}
\end{array}\right.
$$




\subsection{Calculating the weights of risk factors with PF-LPM}

In order to overcome drawback that three risk factors $(\mathrm{S}, \mathrm{O}$ and $\mathrm{D})$ are equally weighted in the traditional FMEA method, we propose a new method of weighting risk factors, called PF-LPM, which takes into account subjective weights of risk factors and constructs maximizing deviation by using the Dice similarity-based distance. The concrete process includes the following seven steps.

Step 1. Construct subjective weight matrices of risk factors.

Similar to Step 2 in Section 5.1, the three of seven experts in expert team are invited to rate weight of risk factors, and construct subjective weight matrices of risk factors $\omega^{S k}=\left(\omega_{y}^{S k}\right)_{1 \times p}, k=1,2, \mathrm{~L} l$, where $\omega_{y}^{s k}$ indicates subjective weight of $y$ th risk factors given by expert $e_{k}$.

Step 2. Calculate syncretic subjective weight matrix.

In order to obtain more consistent evaluation results, the PFWA operator is utilized to fuse experts' evaluation information. So syncretic subjective weight matrix $\boldsymbol{\omega}^{S}=\left(\alpha_{y}\right)_{1 \times p}$ can be calculated as follows:

$$
\alpha_{y}=\operatorname{PFWA}\left(\omega_{y}^{S 1}, \omega_{y}^{S 2}, \omega_{y}^{S 3}\right)=\bigoplus_{k=1}^{3}\left(w_{k} \omega_{y}^{S k}\right)=\left(1-\prod_{k=1}^{3}\left(1-a_{y}^{S k}\right)^{w_{k}}, \prod_{k=1}^{3}\left(b_{y}^{S k}\right)^{w_{k}}, \prod_{k=1}^{3}\left(c_{y}^{S k}\right)^{w_{k}}\right)
$$

where $\omega_{y}^{S k}=\left(a_{y}^{S k}, b_{y}^{S k}, c_{y}^{S k}\right)$ and $\boldsymbol{w}=\left(w_{1}, w_{2}, w_{3}\right)^{T}$ is weight vector of experts, it can be calculated by a weighted generation method based on the normal distribution. Moreover, $w_{k}>0$ and $\sum_{k=1}^{3} w_{k}=1$.

Step 3. Determine subjective weight vector of risk factors.

Based on score function of PFNs, we can determine subjective weight vector of risk factors as follows:

$$
\omega_{y}^{S}=\frac{\left|S\left(\alpha_{y}\right)\right|}{\sum_{y=1}^{p}\left|S\left(\alpha_{y}\right)\right|}
$$

Where $\omega_{y}^{S}$ indicates the subjective weight of $y$ th risk factor.

Step 4. Calculate syncretic decision matrix.

In order to obtain more consistent evaluation results, the PFWG operator is utilized to fuse standardized PFNs decision matrices. So syncretic decision matrix $\boldsymbol{X}=\left(x_{i y}\right)_{m \times p}$ can be calculated as follows:

$$
x_{i y}=P F W G\left(x_{i y}^{1}, x_{i y}^{2}, x_{i y}^{3}\right)=\bigotimes_{k=1}^{3}\left(x_{i y}^{k}\right)^{w_{k}}=\left(\prod_{k=1}^{3}\left(a_{i y}^{k}\right)^{w_{k}}, 1-\prod_{k=1}^{3}\left(1-b_{i y}^{k}\right)^{w_{k}}, 1-\prod_{k=1}^{3}\left(1-c_{i y}^{k}\right)^{w_{k}}\right)
$$

Where $x_{i y}^{k}=\left(a_{i y}^{k}, b_{i y}^{k}, c_{i y}^{k}\right)$.

Step 5. Establish linear programming model.

For a risk evaluation process, if the evaluation values of all failure modes under a risk factor are more different, which indicates this risk factor has a significant contribution to the final ranking of failure modes. Conversely, if the evaluation values of all failure modes under a risk factor have few differences, which indicates that this risk factor has a lower contribution to the final ranking of failure modes. Therefore, for the risk factor that has large differences in evaluation values, it should be assigned a greater weight. Otherwise, it should be assigned a smaller weight. In order to describe these differences, the concept of synthetical deviation is introduced based on the Dice similarity-based distance. It is defined as follows:

$$
D\left(\omega^{o}\right)=\frac{1}{m-1} \sum_{y=1}^{p} \sum_{i=1}^{m} \sum_{h=1, h \neq i}^{m} d_{D S}\left(x_{i y}, x_{h y}\right) \omega_{y}^{O}
$$


Where $\omega_{y}^{o}, y=1,2, \mathrm{~L}, p$ is objective weight of $y$ th risk factors, and $d_{D S}\left(x_{i y}, x_{h y}\right)(i, h=1,2, \mathrm{~L}, m)$ is the Dice similarity-based distance between the evaluation values on failure mode $F M_{i}$ and $F M_{h}$ with respect to risk factor $R F_{j}$.

Based on the fact that the larger the synthetical deviation is, the more reasonable the weights of risk factors are, a linear programming model is established by us to calculate objective weights of risk factors:

$$
\left\{\begin{array}{l}
\operatorname{Max} D\left(\omega^{O}\right)=\frac{1}{m-1} \sum_{y=1}^{p} \sum_{i=1}^{m} \sum_{h=1, h \neq i}^{m} d_{D S}\left(x_{i y}, x_{h y}\right) \omega_{y}^{O} \\
\text { Subjcect to } \sum_{y=1}^{p} \omega_{y}^{O}=1, \omega_{y}^{O} \geq 0, y=1,2, \mathrm{~L}, p
\end{array}\right.
$$

Step 6. Determine objective weight vector of risk factors.

The solution of the above linear programming model is the objective weight vector of risk factors. Therefore, by solving the above model, we can get the objective weight vector of risk factors $\omega^{o}=\left(\omega_{y}^{o}\right)_{1 \times p}$.

Step 7. Determine synthetical weight vector of risk factors.

In the end, the synthetical weight vector of risk factors $\omega=\left(\omega_{y}\right)_{1 \times p}$ can be calculated as follows:

$$
\omega_{y}=\beta \omega_{y}^{S}+(1-\beta) \omega_{y}^{O}
$$

Where $\beta \in[0,1]$ is the importance coefficient of subjective weights.

\subsection{Prioritizing risks with PF-WASPAS method}

In this section, we propose a new extension to WASPAS method under PFSs environment to rank failure modes. It overcomes drawback that ranking mechanism is irrational in the traditional FMEA method. Similar to the VIKOR ranking method, the WASPAS method is a compromise solution method that is based on the idea of weighted sum method (WSM) and weighted product method (WPM). Combined with PFSs, the PF-WASPAS method have an innate superiority in ranking failure modes, because it has many advantages, for instance, it has simple and straightforward process, and follows joint optimality concept for obtaining the final rank of failure modes. Moreover, It determines the final ranking order based on the linear combination of WSM and WPM and also uses PFSs to describe uncertain preference information. The concrete process includes the following five steps.

Step 1. Determine syncretic decision matrix and weights of risk factors.

According to Section 5.2, we can obtain syncretic decision matrix $\boldsymbol{X}=\left(x_{i y}\right)_{m \times p}$ and weight vector of risk factors $\omega=\left(\omega_{y}\right)_{1 \times p}$.

Step 2. Calculate the weighted sum value for each failure modes.

The weighted sum value of $i$ th failure mode can be calculated as follows:

$$
W S M_{i}=\bigoplus_{y=1}^{p} \omega_{y} x_{i y}
$$

Step 3. Calculate the weighted product value for each failure modes.

The weighted product value of $i$ th failure mode can be calculated as follows:

$$
W P M_{i}=\bigotimes_{y=1}^{p}\left(x_{i y}\right)^{\omega_{y}}
$$

Step 4. Calculate the linear combination value of WSM and WPM.

In order to obtain joint optimal solution, we need to calculate the linear combination value of WSM and WPM. 


$$
Q A_{i}=\lambda W S M_{i}+(1-\lambda) W P M_{i}
$$

Where $Q A_{i}$ indicates the obtained linear combination value of $i$ th failure mode, and $\lambda \in[0,1]$ is importance coefficient of the weighted sum value.

Step 5. Rank failure modes.

In order to rank failure modes, it is necessary for us to calculate score function value $Q_{i}$ of the linear combination value of each failure mode.

$$
Q_{i}=S\left(Q A_{i}\right)
$$

If any failure modes have the same $Q_{i}$ values, we need to calculate accuracy function value, and based on Definition 4, the values are assigned in descending order, that is, the failure mode with maximum value is ranked first. For critical failure modes, it is necessary for us take the corresponding corrective measures to eliminate them.

\section{An illustrative example}

\subsection{Background}

In order to explain the implementation process of the proposed FMEA method, in this paper, we take the pallet exchange rack of a horizontal machining center produced by a large CNC machine tool manufacturing company in China as research object. The pallet exchange rack is an important functional part of the horizontal machining center. Its main function is to realize the position exchange between the processed workpiece and the blank to be processed, so as to send the blank to be processed to the processing position, and realize the automatic positioning of the workpiece. At the same time, the processed workpiece is sent out of the processing position. The structure of the pallet exchange rack is presented in Fig. 2, which mainly includes pallet lifting mechanism driven by the hydraulic lifting cylinder and pallet rotating mechanism driven by the hydraulic rotating cylinder. When working, the bracket 4 is lifted by the hydraulic lifting cylinder first. Then, the rack is driven by the rotating hydraulic cylinder, and is meshed with gear shaft 5 to realize the rotation of the bracket 4 . There are two pallets, the included angle between the two pallets is 180 degrees, and they can rotate around the mandrel 3. The two pallets are symmetrically arranged with the mandrel 3 as the center, and when working, the blank and the processed workpiece are respectively placed on these two pallets. When the pallet rotates 180 degrees, the position of the blank and the processed workpiece can be exchanged. The rotating hydraulic cylinder is a hydraulic cylinder with buffer device, and when the bracket 4 quickly rotates to the correct position, the buffer device can make the rotating bracket 4 decelerate and buffer automatically.

As core part of horizontal machining center, the reliability of pallet exchange rack has a great impact on the reliability of the horizontal machining center. Therefore, in order to improve quality and reliability of horizontal machining center, it is necessary and interesting for us to conduct a FMEA for pallet exchange rack, find out the key failure modes of pallet exchange rack and take corresponding corrective measures to eliminate them.

\subsection{Implementation}

In this section, we conduct a risk evaluation process based on the proposed FMEA method to find out key risks of pallet exchange rack and take corresponding corrective measures to eliminate them, thus improve quality and reliability of pallet exchange rack. According to Fig. 1, we can obtain that the proposed FMEA method includes three main processes: risk evaluation, calculating the weights of risk factors, and prioritizing risks. Then, we will introduce the whole implementation process in detail.

Step 1. Risk evaluation.

Considering that this horizontal machining center is produced by a large $\mathrm{CNC}$ machine tool manufacturing company in China, so the members of the technical team and the expert team are selected from the employees of this company. For the technical team, it is composed of fifteen basic technical staffs in the company, who come from five different departments: design, manufacturing, technical service, business and production management, each with 3-5 years of experience in CNC machine tool 
manufacturing industry. For the expert team, it is composed of seven senior technical staffs in the company, who come from five different team too, but each with more than 15 years of experience.

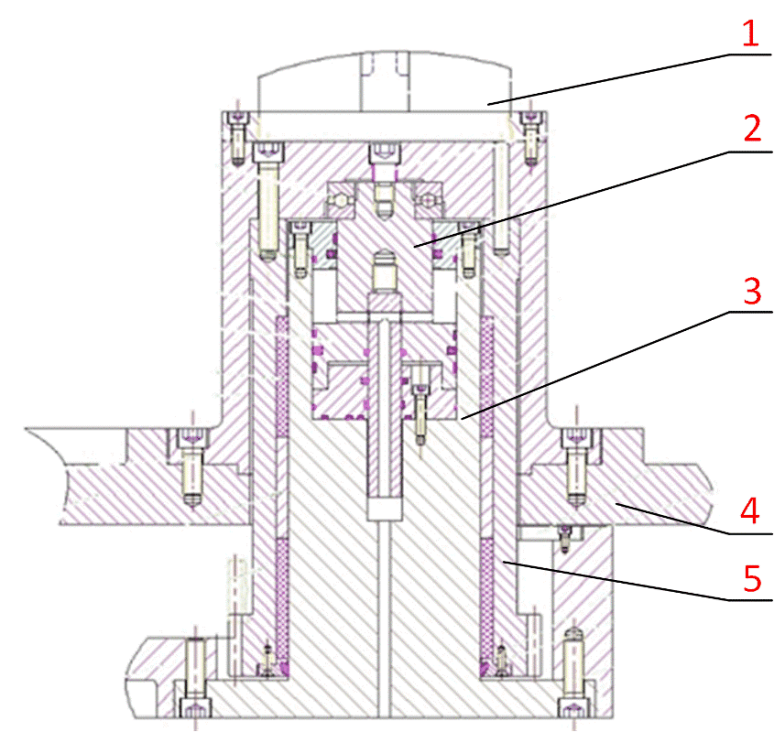

Fig. 2. Structure diagram of pallet exchange rack. 1. exchange rack, 2. piston, 3. mandrel, 4. bracket, 5. gear shaft

After establishing the technical team and the expert team, the staffs in the technical team are invited to collect product data, which includes design drawings, design specification and fault data of pallet exchange rack, and to establish failure tree based on product data collected, as shown in Fig. 3. After that, the traditional FMEA of pallet exchange rack is carried out by the technical team, the results are presented as Table 2. Based on Fig. 3 and Table 2, three of seven experts $e_{k}(k=1,2, \mathrm{~L} l), l=3$ are invited to determine potential failure modes that cause system failure and risk factors of pallet exchange rack. The pallet exchange rack has seven potential failure modes, denoted by $F M=\left\{F M_{1}, F M_{2} \mathrm{~L} F M_{m}\right\}, m=7$, and three risk factors, denoted by $R F=\left\{R F_{1}, R F_{2}, \mathrm{~L} R F_{p}\right\}=\{S, O, D\}, p=3$.

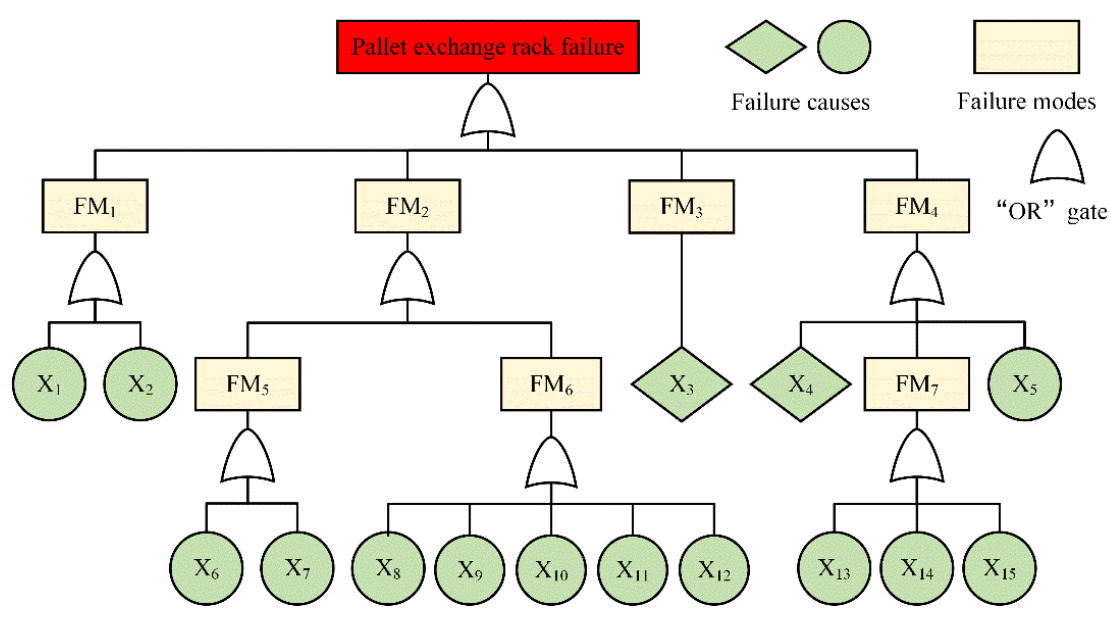

Fig. 3. Failure tree of pallet exchange rack

Table 2 The FMEA of the pallet exchange rack

\begin{tabular}{|c|c|c|c|c|c|c|}
\hline NO. & Failure modes & Failure causes & $\mathrm{S}$ & $\mathrm{O}$ & $\mathrm{D}$ & RPN \\
\hline $\mathrm{FM}_{1}$ & $\begin{array}{l}\text { The pallet was not exchanged to the } \\
\text { correct position }\end{array}$ & $\begin{array}{l}X_{1} \text { : The pallet did not lift to the correct position; } \\
X_{2} \text { : The pallet did not rotate to the correct position }\end{array}$ & 8 & 6 & 7 & 336 \\
\hline $\mathrm{FM}_{2}$ & $\begin{array}{l}\text { The speed of pallet exchange was } \\
\text { too fast or too slow }\end{array}$ & $\begin{array}{l}\mathrm{FM}_{5} \\
\mathrm{FM}_{6}\end{array}$ & 4 & 7 & 6 & 168 \\
\hline $\mathrm{FM}_{3}$ & $\begin{array}{l}\text { The pallet collided with magazine } \\
\text { door during the exchange }\end{array}$ & $\mathrm{X}_{3}$ : Control program error & 8 & 3 & 3 & 72 \\
\hline
\end{tabular}




\begin{tabular}{|c|c|c|c|c|c|c|}
\hline $\mathrm{FM}_{4}$ & Pallet exchange stagnation & $\begin{array}{l}\mathrm{X}_{4} \text { : Control program error; } \mathrm{FM}_{7} \\
\mathrm{X}_{5} \text { : Detection switch fault }\end{array}$ & 6 & 4 & 6 & 144 \\
\hline $\mathrm{FM}_{5}$ & The hydraulic flow was too large & $\begin{array}{l}\mathrm{X}_{6} \text { : The adjustment of throttle valve is unreasonable; } \\
\mathrm{X}_{7} \text { : throttle valve failure }\end{array}$ & 4 & 5 & 6 & 120 \\
\hline $\mathrm{FM}_{6}$ & The hydraulic flow was too small & $\begin{array}{l}\mathrm{X}_{8} \text { : The adjustment of throttle valve is unreasonable; } \\
\mathrm{X}_{9} \text { : throttle valve failure; } \\
\mathrm{X}_{10} \text { : The solenoid valve is blocked; } \\
\mathrm{X}_{11} \text { : The pipeline is blocked; } \\
\mathrm{X}_{12} \text { : The solenoid valve fault }\end{array}$ & 4 & 6 & 6 & 144 \\
\hline $\mathrm{FM}_{7}$ & Hydraulic failure & $\begin{array}{l}\mathrm{X}_{13}: \text { The solenoid valve is blocked; } \\
\mathrm{X}_{14}: \text { The pipeline is blocked; } \\
\mathrm{X}_{15}: \text { The solenoid valve fault }\end{array}$ & 6 & 7 & 4 & 168 \\
\hline
\end{tabular}

In the same vein, we invite three of seven experts from expert team to rate risks based on Table 1, and establish linguistic terms decision matrices $\boldsymbol{T}^{k}=\left(T_{i y}^{k}\right)_{7 \times 3}, k=1,2,3 ; i=1,2, \mathrm{~L} 7 ; y=1,2,3$. The evaluation results is shown in Table 3. For example, the evaluation information of failure mode $\mathrm{FM}_{1}$ with respect to risk factor S given by expert $e_{1}$ is VVH. Then, according to Table 1, all linguistic terms will be translated into corresponding PFNs, and we can obtain PFNs decision matrices. For instance, VVH $\rightarrow(1,0,0)$. Because risk factors have two types, benefit type (D) and cost type (S and D), we need to standardize PFNs decision matrices. Based on Eq. (12), we can obtain standardized PFNs decision matrices $\boldsymbol{X}^{k}=\left(X_{i y}^{k}\right)_{7 \times 3}, k=1,2,3$, the results are presented in Table 4. For example, $\mathrm{H}:(0.8,0.1,0.05) \rightarrow \overline{\mathrm{H}}:(0.05,0.1,0.8)$

Table 3 Linguistic terms decision matrices

\begin{tabular}{|c|c|c|c|c|c|c|c|c|}
\hline \multirow{2}{*}{$e$} & \multirow{2}{*}{ Risk factors } & \multicolumn{7}{|c|}{ Failure modes } \\
\hline & & $\mathrm{FM}_{1}$ & $\mathrm{FM}_{2}$ & $\mathrm{FM}_{3}$ & $\mathrm{FM}_{4}$ & $\mathrm{FM}_{5}$ & $\mathrm{FM}_{6}$ & $\mathrm{FM}_{7}$ \\
\hline \multirow{4}{*}{$e_{1}$} & S & VVH & $\mathrm{L}$ & VVH & VH & $\mathrm{L}$ & $\mathrm{L}$ & VH \\
\hline & $\mathrm{O}$ & $\mathrm{F}$ & $\mathrm{L}$ & VVL & VL & $\mathrm{L}$ & $\mathrm{H}$ & VH \\
\hline & $\mathrm{D}$ & $\mathrm{H}$ & $\mathrm{H}$ & $\mathrm{F}$ & $\mathrm{H}$ & $\mathrm{H}$ & $\mathrm{H}$ & $\mathrm{L}$ \\
\hline & S & VH & $\mathrm{F}$ & VVH & $\mathrm{H}$ & $\mathrm{L}$ & $\mathrm{L}$ & $\mathrm{H}$ \\
\hline \multirow[t]{3}{*}{$e_{2}$} & $\mathrm{O}$ & $\mathrm{H}$ & $\mathrm{F}$ & VL & $\mathrm{L}$ & $\mathrm{L}$ & $\mathrm{H}$ & $\mathrm{H}$ \\
\hline & $\mathrm{D}$ & VH & $\mathrm{H}$ & $\mathrm{F}$ & $\mathrm{F}$ & $\mathrm{H}$ & $\mathrm{H}$ & $\mathrm{F}$ \\
\hline & S & VH & $\mathrm{F}$ & VVH & VH & $\mathrm{L}$ & $\mathrm{L}$ & VH \\
\hline \multirow[t]{2}{*}{$e_{3}$} & $\mathrm{O}$ & $\mathrm{F}$ & $\mathrm{F}$ & VL & $\mathrm{L}$ & $\mathrm{L}$ & $\mathrm{F}$ & $\mathrm{H}$ \\
\hline & $\mathrm{D}$ & VH & $\mathrm{H}$ & $\mathrm{H}$ & $\mathrm{H}$ & VH & VH & $\mathrm{F}$ \\
\hline
\end{tabular}

Table 4 Standardized PFNs decision matrices

\begin{tabular}{|c|c|c|c|c|c|c|c|c|}
\hline \multirow{2}{*}{$e$} & \multirow{2}{*}{$\begin{array}{l}\text { Risk } \\
\text { factors }\end{array}$} & \multicolumn{7}{|l|}{ Failure modes } \\
\hline & & $\mathrm{FM}_{1}$ & $\mathrm{FM}_{2}$ & $\mathrm{FM}_{3}$ & $\mathrm{FM}_{4}$ & $\mathrm{FM}_{5}$ & $\mathrm{FM}_{6}$ & $\mathrm{FM}_{7}$ \\
\hline \multirow{4}{*}{$e_{1}$} & S & $(0,0,1)$ & $(0.2,0.45,0.25)$ & $(1,0,0)$ & $(0.9,0.05,0)$ & $(0.2,0.45,0.25)$ & $(0.2,0.45,0.25)$ & $(0.9,0.05,0)$ \\
\hline & $\mathrm{O}$ & $(0.45,0.4,0.1)$ & $(0.2,0.45,0.25)$ & $(0,0,1)$ & $(0,0.05,0.9)$ & $(0.2,0.45,0.25)$ & $(0.8,0.1,0.05)$ & $(0.9,0.05,0)$ \\
\hline & $\mathrm{D}$ & $(0.05,0.1,0.8)$ & $(0.05,0.1,0.8)$ & $(0.1,0.4,0.45)$ & $(0.05,0.1,0.8)$ & $(0.05,0.1,0.8)$ & $(0.05,0.1,0.8)$ & $(0.25,0.45,0.2)$ \\
\hline & S & $(0.9,0.05,0)$ & $(0.45,0.4,0.1)$ & $(1,0,0)$ & $(0.8,0.1,0.05)$ & $(0.2,0.45,0.25)$ & $(0.2,0.45,0.25)$ & $(0.8,0.1,0.05)$ \\
\hline \multirow[t]{3}{*}{$e_{2}$} & $\mathrm{O}$ & $(0.8,0.1,0.05)$ & $(0.45,0.4,0.1)$ & $(0,0.05,0.9)$ & $(0.2,0.45,0.25)$ & $(0.2,0.45,0.25)$ & $(0.8,0.1,0.05)$ & $(0.8,0.1,0.05)$ \\
\hline & $\mathrm{D}$ & $(0,0.05,0.9)$ & $(0.05,0.1,0.8)$ & $(0.1,0.4,0.45)$ & $(0.1,0.4,0.45)$ & $(0.05,0.1,0.8)$ & $(0.05,0.1,0.8)$ & $(0.1,0.4,0.45)$ \\
\hline & $\mathrm{S}$ & $(0.9,0.05,0)$ & $(0.45,0.4,0.1)$ & $(1,0,0)$ & $(0.9,0.05,0)$ & $(0.2,0.45,0.25)$ & $(0.2,0.45,0.25)$ & $(0.9,0.05,0)$ \\
\hline \multirow[t]{2}{*}{$e_{3}$} & $\mathrm{O}$ & $(0.45,0.4,0.1)$ & $(0.45,0.4,0.1)$ & $(0,0.05,0.9)$ & $(0.2,0.45,0.25)$ & $(0.2,0.45,0.25)$ & $(0.45,0.4,0.1)$ & $(0.8,0.1,0.05)$ \\
\hline & $\mathrm{D}$ & $(0,0.05,0.9)$ & $(0.05,0.1,0.8)$ & $(0.05,0.1,0.8)$ & $(0.05,0.1,0.8)$ & $(0,0.05,0.9)$ & $(0,0.05,0.9)$ & $(0.1,0.4,0.45)$ \\
\hline
\end{tabular}


Step 2. Calculating the weights of risk factors with PF-LPM.

In this section, we adopt PF-LPM to calculate weights of risk factors. It mainly includes calculating subjective weights and calculating objective weights. In the calculation process of subjective weights, similar to Step 1, we invite three of seven experts to rate risk factors, the evaluation results are shown in Table 5. For example, the evaluation information of risk factor $\mathrm{S}$ given by experts $e_{1}$ is $\mathrm{H}$. Then, all linguistic terms will be translated into corresponding PFNs, so the subjective weight matrices $\omega^{S k}=\left(\omega_{y}^{s k}\right)_{1 \times 3}, k=1,2,3$ can be obtained.

Based on Eq. 13, the experts' evaluation information are fused by PFWA operator. The weights of experts is $\boldsymbol{w}=(0.2,0.45,0.35)$, which can be calculated by a weighted generation method based on the normal distribution. Then, we can obtain syncretic subjective weight matrix of risk factors $\omega^{s}=\left(\alpha_{y}\right)_{3}$, the fused results are presented in Table 5. For instance,

$$
\alpha_{1}=P F W A\left(\omega_{1}^{S 1}, \omega_{1}^{S 2}, \omega_{1}^{S 3}\right)=P F W A((0.8,0.1,0.05),(0.9,0.05,0),(0.9,0.05,0))=(0.8851,0.0574,0)
$$

According to Eq. (14), the subjective weights vector of risk factors can be obtained, that is, $\omega^{S}=(0.5458,0.0978,0.3564)$. For example, $\omega_{1}^{S}=\frac{\left|S\left(\alpha_{1}\right)\right|}{\sum_{y=1}^{3}\left|S\left(\alpha_{y}\right)\right|}=\frac{|0.8851-0|}{|0.8851-0|+|0.3241-0.1655|+|0.6511-0.0732|}=0.5458$.

Table 5 The subjective weight matrices and syncretic subjective weight matrix of risk factors

\begin{tabular}{|c|c|c|c|c|c|c|}
\hline \multirow{2}{*}{ Experts } & \multicolumn{6}{|c|}{ Risk factors } \\
\hline & $\mathrm{S}$ & $\mathrm{O}$ & $\mathrm{D}$ & S & $\mathrm{O}$ & $\mathrm{D}$ \\
\hline$e_{1}$ & $\mathrm{H}$ & $\mathrm{L}$ & $\mathrm{F}$ & $(0.8,0.1,0.05)$ & $(0.2,0.45,0.25)$ & $(0.45,0.4,0.1)$ \\
\hline$e_{2}$ & VH & $\mathrm{F}$ & $\mathrm{H}$ & $(0.9,0.05,0)$ & $(0.45,0.4,0.1)$ & $(0.8,0.1,0.05)$ \\
\hline$e_{3}$ & VH & $\mathrm{L}$ & $\mathrm{F}$ & $(0.9,0.05,0)$ & $(0.2,0.45,0.25)$ & $(0.45,0.4,0.1)$ \\
\hline$\alpha_{y}$ & & & & $(0.8851,0.0574,0)$ & $(0.3241,0.4268,0.1655)$ & $(0.6511,0.2144,0.0732)$ \\
\hline$\omega_{y}^{S}$ & & & & 0.5458 & 0.0978 & 0.3564 \\
\hline
\end{tabular}

In the calculation process of objective weights, firstly, we need to fuse experts' evaluation information based on Eq. (15) to obtain the syncretic decision matrix $\boldsymbol{X}=\left(x_{i y}\right)_{7 \times 3}$. The fused results are presented in Table A.1 of Appendix A. For example,

$$
x_{11}=P F W G\left(x_{11}^{1}, x_{11}^{2}, x_{11}^{3}\right)=P F W G((0,0,1),(0.9,0.05,0),(0.9,0.05,0))=(0.9192,0.0402,0)
$$

Then, we need to calculate synthetical deviation and establish linear programming model. Based on Eq. (16), we can obtain synthetical deviation about objective weights of risk factors as follows:

$$
D\left(\omega^{o}\right)=\frac{1}{6}\left(13.4492 \omega_{1}^{o}+18.2079 \omega_{2}^{o}+3.8432 \omega_{3}^{o}\right)
$$

Where deviation $d_{D S}\left(x_{i y}, x_{h y}\right), i, h=1,2, \mathrm{~L} 7$ and $i \neq h ; y=1,2,3$ can be calculated by using the Dice similarity-based distance, for instance, $d_{D S}\left(x_{11}, x_{21}\right)=1-\frac{2 \times(0.9192 \times 0.3826+0.0402 \times 0.4104+0 \times 0.1322)}{0.9192^{2}+0.0402^{2}+0^{2}+0.3826^{2}+0.4104^{2}+0.1322^{2}}=0.3753$.

After that, we can construct a linear programming model based on Eq. (17) as follows:

$$
\left\{\begin{array}{l}
\operatorname{Max} D\left(\omega^{O}\right)=\frac{1}{6}\left(13.4492 \omega_{1}^{O}+18.2079 \omega_{2}^{O}+3.8432 \omega_{3}^{o}\right) \\
\text { Subjcect to } \sum_{y=1}^{3} \omega_{y}^{o}=1, \omega_{y}^{o} \geq 0, y=1,2,3
\end{array}\right.
$$


By solving the above linear programming model, we can obtain objective weight vector of risk factors.

$$
\omega^{o}=(0.3788,0.5129,0.1083)
$$

Finally, based on Eq. (18), we can assume that $\beta=0.5$, and obtain the synthetical weight vector of risk factors

$$
\omega^{S}=(0.4623,0.3054,0.2323)
$$

Step 3. Prioritizing risks with PF-WASPAS method.

In this section, the PF-WASPAS method will be utilized to ranking failure modes of pallet exchange rack. According to the above calculation, we have obtain the syncretic decision matrix $\boldsymbol{X}=\left(x_{i y}\right)_{7 \times 3}$ and the synthetical weight vector of risk factors $\omega^{S}=(0.4623,0.3054,0.2323)$

Then, based on Eq. (19) and (20), we can calculate the weighted sum value and the weighted product value of each failure mode, for instance,

$$
\begin{gathered}
W S M_{1}=\bigoplus_{y=1}^{3} \omega_{y} x_{1 y}=0.4623(0.9192,0.0402,0) \oplus 0.3054(0.583,0.2799,0.0778) \oplus 0.2323(0,0.0602,0.8851) \\
=(0.7607,0.0799,0) \\
W P M_{1}=\bigotimes_{y=1}^{3}\left(x_{1 y}\right)^{\omega_{y}}=(0.9192,0.0402,0)^{0.4623} \otimes(0.583,0.2799,0.0778)^{0.3054} \otimes(0,0.0602,0.8851)^{0.2323}=(0,0.1251,0.4099)
\end{gathered}
$$

The calculated results are shown in Table A.2 of Appendix A. Based on Eq. (21), we can assume that $\lambda=0.5$, and obtain the linear combination value of WSM and WPM. For instance,

$$
Q A_{1}=0.5(0.7607,0.0799,0)+(1-0.5)(0,0.1251,0.4099)=(0.5108,0.1,0)
$$

The calculated results of other failure modes are shown in Table A.2 of Appendix A.

At last, the score function value of the linear combination value of each failure mode can be calculated based on Eq. (22), and based on these values, the failure modes are assigned in descending order, that is, the failure mode with maximum value is ranked first. Therefore, the final ranking results of all failure modes are $\mathrm{FM}_{1}>\mathrm{FM}_{7}>\mathrm{FM}_{6}>\mathrm{FM}_{5}>\mathrm{FM}_{2}>\mathrm{FM}_{4}>\mathrm{FM}_{3}$.

According to the ranking results, we can obtain that failure mode $\mathrm{FM}_{1}$ should be given the highest priority for risk mitigation and safety improvement. Based on Table 2, the reasons that cause failure mode $\mathrm{FM}_{1}$ mainly include the pallet did not lift to the correct position and the pallet did not rotate to the correct position. The rotation and lifting of the exchange rack are controlled by the hydraulic system and the limit switch, therefore, we can take the following measures to eliminate it: (1) Checking the limit switch regularly; (2) Checking the solenoid valve regularly and pipeline, and timely replace the defective pipeline; (3) Debugging the program before machining; (4) Ensuring accurate engagement of gear and rack.

\section{Discussion and comparison}

In this section, a discussion and comparison process is carried out by us to verify the rationality and effectiveness of the proposed method, it mainly includes three parts: sensitivity analysis of different distance measures, comparison analysis of different ranking methods, and managerial implications.

\subsection{Sensitivity analysis of different distance measures}

According to Section 2, we know that many distance measure methods have been proposed to describe the differences between two PFSs. When different distance measures are utilized to calculate the synthetical deviation, we can obtain different weights of risk factors, which may lead to different ranking results. Therefore, it is necessary and interesting for us to explore the influence of different distance measures on failure modes' ranking.

In order to conduct sensitivity analysis of different distance measures, the traditional distance, the Ganie's distance, the Singh's distance and the proposed Dice similarity-based distance are used by us to calculate weights of risk factors, and rank 
failure modes based on the above case. The concept of the Ganie's distance was first proposed by Ganie in 2021 (Ganie \& Singh), it is defined as follows:

Definition 13. Let $T_{1}=\left\langle a_{1}\left(x_{i}\right), b_{1}\left(x_{i}\right), c_{1}\left(x_{i}\right)\right\rangle$ and $T_{2}=\left\langle a_{2}\left(x_{i}\right), b_{2}\left(x_{i}\right), c_{2}\left(x_{i}\right)\right\rangle$ be two PFSs in a given finite set $X=\left\{x_{1}, x_{2}, \mathrm{~L} x_{n}\right\}$.

Then, the Ganie's distance measure between $T_{1}$ and $T_{2}$ can be obtained as follows:

$$
D_{G}\left(T_{1}, T_{2}\right)=1-\frac{1}{4 n} \sum_{i=1}^{n}\left[\begin{array}{l}
3 \sqrt{a_{1}\left(x_{i}\right) a_{2}\left(x_{i}\right)}+3 \sqrt{b_{1}\left(x_{i}\right) b_{2}\left(x_{i}\right)}+3 \sqrt{c_{1}\left(x_{i}\right) c_{2}\left(x_{i}\right)}+3 \sqrt{\pi_{1}\left(x_{i}\right) \pi_{2}\left(x_{i}\right)} \\
+\sqrt{\left(1-a_{1}\left(x_{i}\right)-b_{1}\left(x_{i}\right)\right)\left(1-a_{2}\left(x_{i}\right)-b_{2}\left(x_{i}\right)\right)} \\
+\sqrt{\left(1-a_{1}\left(x_{i}\right)-c_{1}\left(x_{i}\right)\right)\left(1-a_{2}\left(x_{i}\right)-c_{2}\left(x_{i}\right)\right)} \\
+\sqrt{\left(1-b_{1}\left(x_{i}\right)-c_{1}\left(x_{i}\right)\right)\left(1-b_{2}\left(x_{i}\right)-c_{2}\left(x_{i}\right)\right)}
\end{array}\right]
$$

The concept of the Singh's distance was proposed by Singh in 2018 (Singh et al., 2018), it is defined as follows:

Definition 14. Let $T_{1}=\left\langle a_{1}\left(x_{i}\right), b_{1}\left(x_{i}\right), c_{1}\left(x_{i}\right)\right\rangle$ and $T_{2}=\left\langle a_{2}\left(x_{i}\right), b_{2}\left(x_{i}\right), c_{2}\left(x_{i}\right)\right\rangle$ be two PFSs in a given finite set $X=\left\{x_{1}, x_{2}, \mathrm{~L} x_{n}\right\}$. Then, the Singh's distance measure between $T_{1}$ and $T_{2}$ can be obtained as follows:

$$
D_{S}\left(T_{1}, T_{2}\right)=1-\left[\frac{1}{4 n} \sum_{i=1}^{n} \max \left(\left|a_{1}\left(x_{i}\right)-a_{2}\left(x_{i}\right)\right|^{2},\left|b_{1}\left(x_{i}\right)-b_{2}\left(x_{i}\right)\right|^{2},\left|c_{1}\left(x_{i}\right)-c_{2}\left(x_{i}\right)\right|^{2},\left|\pi_{1}\left(x_{i}\right)-\pi_{2}\left(x_{i}\right)\right|^{2}\right)\right]^{\frac{1}{2}}
$$

The final ranking results of these four distance measures are shown in Table 6. In order to provide a more visual comparison, a line chart is utilized by us to describe the final ranking results, as shown in Fig. 4.

Table 6 Sensitivity analysis results

\begin{tabular}{lllllllll}
\hline Failure & \multicolumn{2}{l}{ The traditional distance } & \multicolumn{2}{c}{ The Ganie's distance } & \multicolumn{2}{c}{ The Singh's distance } & \multicolumn{2}{c}{ The Dice similarity-based distance } \\
\cline { 2 - 8 } modes & $Q_{i}$ & Ranking & $Q_{i}$ & Ranking & $Q_{i}$ & Ranking & $Q_{i}$ & Ranking \\
\hline FM $_{1}$ & 0.0231 & 3 & 0.6352 & 1 & 0.6237 & 2 & 1 & 1 \\
$\mathrm{FM}_{2}$ & -0.5581 & 7 & -0.0024 & 5 & 0.2206 & 5 & 0.0018 & 5 \\
$\mathrm{FM}_{3}$ & 0.6328 & 1 & 0.1524 & 4 & -0.0926 & 7 & -0.3162 & 7 \\
$\mathrm{FM}_{4}$ & -0.2891 & 5 & -0.2475 & 6 & 0.0045 & 6 & -0.1215 & 6 \\
$\mathrm{FM}_{5}$ & -0.1287 & 4 & -0.3377 & 7 & 0.3521 & 4 & 0.1403 & 4 \\
$\mathrm{FM}_{6}$ & -0.3872 & 6 & 0.2647 & 3 & 0.4375 & 3 & 0.5108 & 3 \\
$\mathrm{FM}_{7}$ & 0.3219 & 2 & 0.4926 & 2 & 0.8457 & 1 & 0.5834 & 2 \\
\hline
\end{tabular}

According to Table 6 and Fig. 4, we can obtain that the ranking results of the proposed Dice similarity-based distance are highly related with those of the Ganie's distance and the Singh's distance, but have great difference with those of the traditional distance. For example, except for $\mathrm{FM}_{3}$ and $\mathrm{FM}_{5}$, the ranking results of the Ganie's distance and the proposed Dice similaritybased distance are identical. In the same vein, except for $\mathrm{FM}_{1}$ and $\mathrm{FM}_{7}$, the ranking results of the Singh's distance and the proposed Dice similarity-based distance are identical. However, for the traditional distance, except for $\mathrm{FM}_{5}$ and $\mathrm{FM}_{7}$, the ranking results of the traditional distance and the proposed Dice similarity-based distance are completely different. Moreover, the firstranked and the last-ranked failure modes of the proposed Dice similarity-based distance are consistent with traditional RPN method, that is $\mathrm{FM}_{1}$ and $\mathrm{FM}_{3}$. Therefore, based on above analysis, we can obtain that the proposed Dice similarity-based distance is better than the Ganie's distance and the Singh's distance, and these three distance measures are better than the traditional distance.

\subsection{Comparison analysis of different ranking methods}

When different ranking methods are utilized to rank failure modes of the pallet exchange rack, we can obtain different ranking results. Some of these ranking results are quite different, and some are almost consistent. In order to verify the rationality and effectiveness of the proposed method, in this section, a comparison analysis with respect to the traditional RPN, the intuitionistic fuzzy-linear programming model-multi-attributive border approximation area comparison (IF-LPM-MABAC) method which calculates weights of risk factors with LPM, and ranks failure modes with MABAC method (Liu et al., 2019c), the spherical fuzzy-WASPAS (SF-WASPAS) method (Aydogdu \& Gul, 2020) which calculates weights of risk factors with entropy measure, 
and ranks failure modes with MABAC method and the proposed FMEA method is conducted. Based on the above case, the ranking results of these four methods are shown in Table 7. Similar to Section 7.1, a line chart is utilized by us to describe the final ranking results, as presented in Fig. 5.

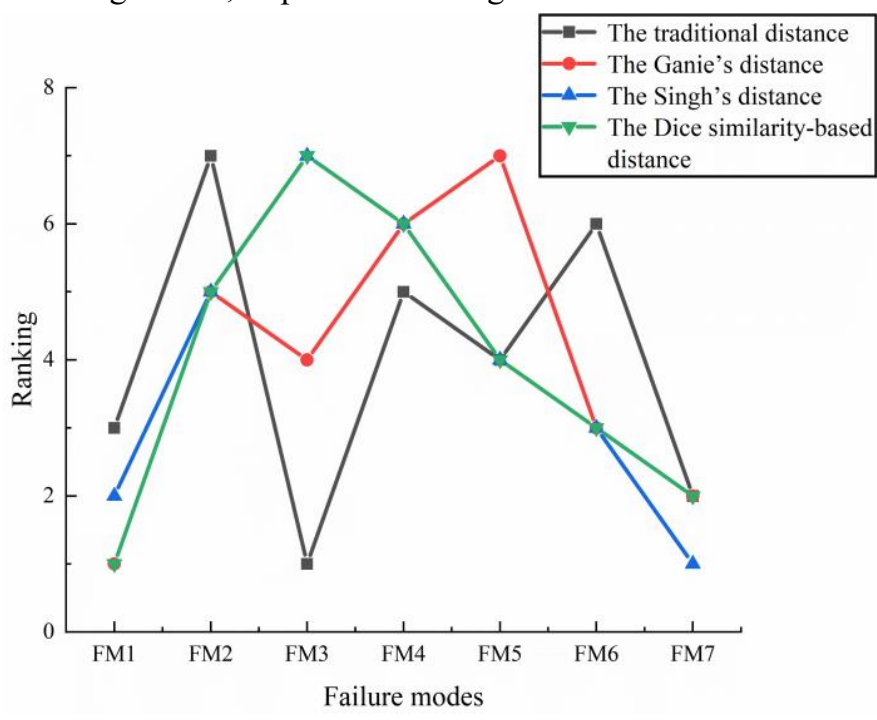

Fig. 4 Sensitivity analysis results

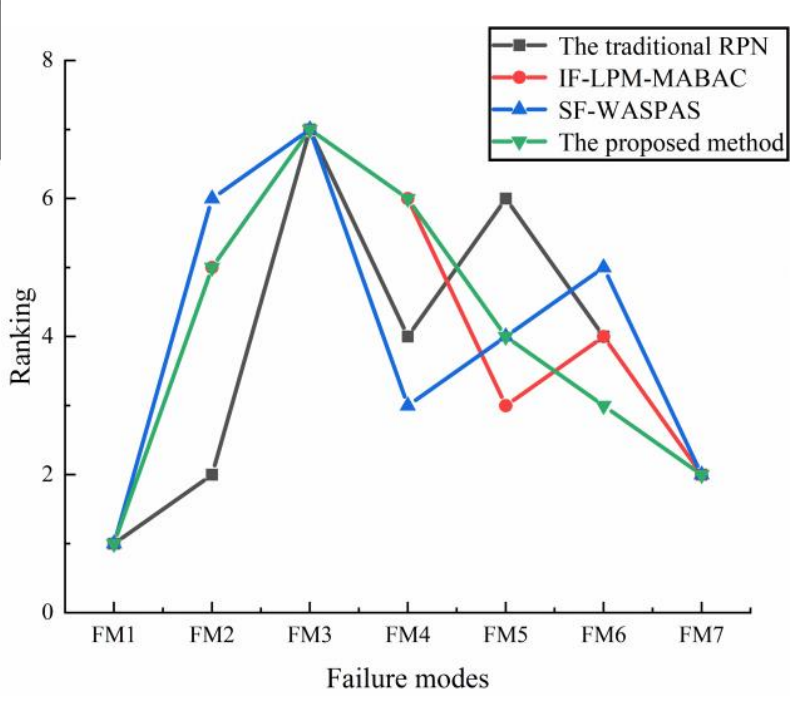

Fig. 5 Comparison analysis results

The comparison of the ranking results mainly includes three aspects. Firstly, in order to find the statistical significance of the difference between the ranking results obtained using the proposed FMEA method and the ones obtained from the traditional RPN method, the IF-LPM-MABAC method and the SF-WASPAS method, the Spearman rank correlation coefficient (SRCC) is utilized by us. It was first proposed by Raju in 1999, and was defined as follows:

$$
R=1-\frac{6 \sum_{i=1}^{m} D_{i}^{2}}{m\left(m^{2}-1\right)}
$$

Where $D_{i}$ is the difference of $i$ th failure mode's ranking in these two methods and $R$ indicates the Spearman rank correlation coefficient value.

The calculated results are presented in Table 7. Based on Table 7, we can obtain that the proposed FMEA method is highly related with the IF-LPM-MABAC method (0.897) and the SF-WASPAS method (0.856), but have great difference with the traditional RPN method (0.427). Moreover, in these four ranking methods, the first-ranked and the last-ranked failure modes are same, that is, $\mathrm{FM}_{1}$ and $\mathrm{FM}_{3}$. Therefore, based on the above rough comparison, we can obtain that the proposed FMEA method is rational.

Table 7 Comparison analysis results

\begin{tabular}{llllllllllll}
\hline Failure & \multicolumn{3}{l}{ The traditional RPN } & \multicolumn{3}{c}{ IF-LPM-MABAC } & \multicolumn{2}{l}{ SF-WASPAS } & \multicolumn{3}{c}{ The proposed method } \\
\cline { 2 - 11 } modes & $\mathrm{S}$ & $\mathrm{O}$ & $\mathrm{D}$ & $R P N_{i}$ & Ranking & $R P V_{i}$ & Ranking & $Q_{i}$ & Ranking & $Q_{i}$ & Ranking \\
\hline $\mathrm{FM}_{1}$ & 8 & 6 & 7 & 336 & 1 & 0.798 & 1 & 0.7665 & 1 & 1 & 1 \\
$\mathrm{FM}_{2}$ & 4 & 7 & 6 & 168 & 2 & -0.015 & 5 & 0.0017 & 6 & 0.0018 & 5 \\
$\mathrm{FM}_{3}$ & 8 & 3 & 3 & 72 & 7 & -0.337 & 7 & -0.3276 & 7 & -0.3162 & 7 \\
$\mathrm{FM}_{4}$ & 6 & 4 & 6 & 144 & 4 & -0.200 & 6 & 0.4912 & 3 & -0.1215 & 6 \\
$\mathrm{FM}_{5}$ & 4 & 5 & 6 & 120 & 6 & 0.516 & 3 & 0.1107 & 4 & 0.1403 & 4 \\
$\mathrm{FM}_{6}$ & 4 & 6 & 6 & 144 & 4 & 0.359 & 4 & 0.0328 & 5 & 0.5108 & 3 \\
$\mathrm{FM}_{7}$ & 6 & 7 & 4 & 168 & 2 & 0.687 & 2 & 0.5487 & 2 & 0.5834 & 2 \\
$K$ & 0.427 & & & & 0.897 & & 0.856 & & 1 \\
\hline
\end{tabular}

Secondly, by comparing ranking results of the proposed FMEA method and the traditional RPN method, we can obtain the proposed FMEA method have innate superiority in overcoming the drawbacks of the traditional RPN method, which is mainly reflected in the following two aspects: (1) In the traditional RPN method, the ranking of failure modes $\mathrm{FM}_{2}$ and $\mathrm{FM}_{7}$ are identical, because they have the same RPN value 168. However, in real life, $\mathrm{FM}_{7}$ should be given higher priority than $\mathrm{FM}_{2}$, that is because the main power of pallet exchange rack comes from hydraulic system, the hydraulic system failure will paralyze the whole pallet 
exchange device. While the speed of pallet exchange was too fast or too slow have little influence on the lifting and rotating motion of the exchange rack. This problem is solved by the proposed FMEA method perfectly. Similarly, $\mathrm{FM}_{6}$ should be given higher priority than $\mathrm{FM}_{4}$; (2) In the traditional FMEA method, the failure mode $\mathrm{FM}_{5}$ ranks the sixth, the failure mode $\mathrm{FM}_{2}$ ranks the second. However, in the proposed FMEA method, the failure mode $\mathrm{FM}_{5}$ ranks the fourth, the failure mode $\mathrm{FM}_{2}$ ranks the fifth, which indicates that $\mathrm{FM}_{5}$ should be given higher priority than $\mathrm{FM}_{2}$, and this ranking result is consistent with those of the other two methods.

Finally, compared with the IF-LPM-MABAC method and the SF-WASPAS method. By comparing the IF-LPM-MABAC method and the proposed FMEA method, based on Table 7 and Fig. 5, we can obtain that the ranking results of the proposed FMEA method are consistent with the IF-LPM-MABAC method, except for $\mathrm{FM}_{5}$ and $\mathrm{FM}_{6}$. The reasons that lead to this phenomenon mainly include the following three aspects: (1) IFSs and PFSs are utilized to rate risks in the IF-LPM-MABAC method and the proposed FMEA method, and PFSs is an extension of FSs and IFSs, which can overcome the drawback that the risks are rated with crisp values, which can't express the uncertainty and hesitation of experts' evaluation information in traditional RPN method; (2) The LPM method is utilized to calculate the weights of risk factors in these two methods, which can overcome the drawback that three risk factors are equally weighted in the traditional RPN method; (3) The ranking mechanism of these two methods are different, one is MABAC method, the other is WASPAS method, both theses two ranking methods can overcome drawback that the ranking mechanism is irrational in the traditional RPN method. In the same vein, by comparing the SF-WASPAS method and the proposed FMEA method, based on Table 7 and Fig. 5, we can obtain that the ranking results of these two methods have slight differences, for instance, $\mathrm{FM}_{2}, \mathrm{FM}_{4}$ and $\mathrm{FM}_{6}$. The reasons that lead to this phenomenon mainly include the following three aspects: (1) SFSs and PFSs are utilized to rate risks in the SF-WASPAS method and the proposed FMEA method; (2) The LPM method is utilized to calculate the weights of risk factors in the proposed FMEA method, while the SF-WASPAS method calculates weights of risk factors with entropy measure; (3) The WASPAS method is utilized to rank failure modes in these two methods. The above mentioned aspects can overcome the drawbacks of the traditional RPN method, too. Therefore, based on the above comparison analysis, we can obtain the proposed FMEA method is rational and effective in ranking failure modes and overcome the drawbacks of the traditional RPN method.

\subsection{Managerial implications}

In order to let the proposed FMEA method be better implemented in the enterprise, for the managers and employees of the company, we give the following five suggestions:

(1) Conducting a training in the company to improve the quality and reliability awareness of employees. For an enterprise, only when the quality and reliability awareness of each employee is improved, the quality and reliability of products can be improved. Therefore, it is necessary for managers to conduct a training with respect to the quality and reliability of products.

(2) Establishing a professional quality and reliability team in the company. In the proposed FMEA method, we need to form a technical team and an expert team to rate risks. To facilitate implementation, the members of the technical team and expert team can be selected from the quality and reliability team.

(3) Arranging the staff to formulate corresponding corrective measures to eliminate or alleviate failure of products based on the ranking results and the actual situation of the company, and invite professional technicians to carry out these formulated corrective measures.

(4) For the important links in the production process, the quality and reliability warning or early warning should be set up. The establishment of quality and reliability warning or early warning can remind employees to pay attention to important links in the production process.

(5) Regularly carrying out quality and reliability communication activities in the company. The improvement of the quality and reliability of a product is the result of the cooperation of various departments, so carrying out such activities is conducive to the communication between various departments.

Therefore, the proposed FMEA method is not only rational and effective, but also applicable. As long as managers manage properly, this method have innate advantages in improving the quality and reality of products and enterprise competitiveness. 


\section{Conclusions}

In this paper, we propose a new risk evaluation method based on PF-LPM and PF-WASPAS. Moreover, in order to calculate the difference between two PFSs, some new distance measures based on the Dice similarity and Jaccard similarity are proposed. In the proposed FMEA method, firstly, PFSs are utilized to rate risks. Secondly, the PFWA operator and PFWG operator are utilized to fuse experts' evaluation information. The synthetical deviation of evaluation information is calculated by using the Dice similarity-based distance, and the weights of risk factors are calculated with the PF-LPM method. Then, the failure modes are ranked with the PF-WASPAS method. At last, we take the pallet exchange rack of a horizontal machining center produced by a large $\mathrm{CNC}$ machine tool manufacturing company in China as research object to explain the implementation process of the proposed FMEA method.

In order to verify the rationality and effectiveness of the proposed method, a discussion with respect to sensitivity analysis of different distance measures, comparison analysis of different ranking methods and managerial implications is conducted. The results of sensitivity analysis indicate that the proposed Dice similarity-based distance is better than the Ganie's distance and the Singh's distance, and these three distance measures are better than the traditional distance. For comparison analysis of the traditional RPN method, the IF-LPM-MABAC method, the SF-WASPAS method and the proposed FMEA method, the comparison results indicate that the proposed FMEA method is rational and valid in ranking failure modes. In order to let the proposed FMEA method be better implemented in the enterprise, we give a managerial implications process. In the future, we will explore interval valued form of PFSs and use them to rate risks. Moreover, we will explore the combination of interval value form of PFS with other weight calculation methods and ranking methods.

\section{Acknowledgments}

This work was financially supported by the National Natural Science Foundation, China (No. 51835001; 51705048); the National Major Scientific and Technological Special Project for "High-grade CNC and Basic Manufacturing Equipment", China (2018ZX04032-001; 2019ZX04005-001).

\section{Conflict of Interest}

$\bigotimes$ The authors declare that they have no known competing financial interests or personal relationships that could have appeared to influence the work reported in this paper.

$\square$ The authors declare the following financial interests/personal relationships which may be considered as potential competing interests:

\section{Ethical approval}

This article does not contain any studies with human participants or animals performed by any of the authors.

\section{Informed consent}

Informed consent was obtained from all individual participants included in the study. 


\section{Appendix A}

Table A.1 The syncretic decision matrix.

\begin{tabular}{|c|c|c|c|c|c|c|c|}
\hline \multirow{2}{*}{$\begin{array}{l}\text { Risk } \\
\text { factors }\end{array}$} & \multicolumn{7}{|l|}{ Failure modes } \\
\hline & $\mathrm{FM}_{1}$ & $\mathrm{FM}_{2}$ & $\mathrm{FM}_{3}$ & $\mathrm{FM}_{4}$ & $\mathrm{FM}_{5}$ & $\mathrm{FM}_{6}$ & $\mathrm{FM}_{7}$ \\
\hline S & $(0.9192,0.0402,0)$ & $(0.3826,0.4104,0.1322)$ & $(1,0,0)$ & $(0.8535,0.0728,0.0228)$ & $(0.2,0.45,0.25)$ & $(0.2,0.45,0.25)$ & $(0.8535,0.0728,0.0228)$ \\
\hline $\mathrm{O}$ & $(0.583,0.2799,0.0778)$ & $(0.3826,0.4104,0.1322)$ & $(0,0.0402,1)$ & $(0,0.3865,0.4988)$ & $(0.2,0.45,0.25)$ & $(0.6541,0.2191,0.0678)$ & $(0.8191,0.0902,0.0402)$ \\
\hline D & $(0,0.0602,0.8851)$ & $(0.05,0.1,0.8)$ & $(0.0785,0.3085,0.614)$ & $(0.0683,0.2501,0.6847)$ & $(0,0.0828,0.8431)$ & $(0,0.0828,0.831)$ & $(0.1201,0.4104,0.4072)$ \\
\hline
\end{tabular}

Table A.2 Ranking results

\begin{tabular}{|c|c|c|c|c|c|c|c|}
\hline \multirow{2}{*}{$\begin{array}{l}\text { Ranking } \\
\text { values }\end{array}$} & \multicolumn{7}{|l|}{ Failure modes } \\
\hline & $\mathrm{FM}_{1}$ & $\mathrm{FM}_{2}$ & $\mathrm{FM}_{3}$ & $\mathrm{FM}_{4}$ & $\mathrm{FM}_{5}$ & $\mathrm{FM}_{6}$ & $\mathrm{FM}_{7}$ \\
\hline$W S M_{i}$ & $(1,0,0)$ & $(0.3176,0.2956,0.2009)$ & $(0.1574,0.3037,0.3316)$ & $(0.3478,0.2438,0.2226)$ & $(0.5953,0.1615,0.129)$ & $(0.7607,0.0799,0)$ & $(0.7631,0.1162,0.053)$ \\
\hline$W P M_{i}$ & $(0,0.0935,1)$ & $(0.2385,0.3495,0.3829)$ & $(0,0.3806,0.4785)$ & $(0,0.3106,0.4427)$ & $(0,0.222,0.3872)$ & $(0,0.1251,0.4099)$ & $(0.5345,0.1702,0.1347)$ \\
\hline$Q A_{i}$ & $(1,0,0)$ & $(0.2791,0.3214,0.2773)$ & $(0.0821,0.34,0.3983)$ & $(0.1924,0.2752,0.3139)$ & $(0.3638,0.1893,0.2235)$ & $(0.5108,0.1,0)$ & $(0.6679,0.1406,0 . .0845)$ \\
\hline$Q_{i}$ & 1 & 0.0018 & -0.3162 & -0.1215 & 0.1403 & 0.5108 & 0.5834 \\
\hline $\begin{array}{l}\text { Ranking } \\
\text { results }\end{array}$ & 1 & 5 & 7 & 6 & 4 & 3 & 2 \\
\hline
\end{tabular}




\section{References}

Chen, Y.F., Ran, Y., Wang, Z.C. \& Zhang, G.B. Research on global coupling analysis and approximate decoupling of quality characteristics in the early design stage. Proceedings of the Institution of Mechanical Engineers Part C-Journal of Mechanical Engineering Science, 12. DOI:10.1177/0954406220934844.

Jin, C.X., Ran, Y., Wang, Z.C., Huang, G.Q., Xiao, L.M. \& Zhang, G.B. (2020). Reliability analysis of gear rotation meta-action unit based on Weibull and inverse Gaussian competing failure process. Engineering Failure Analysis, 117, 16. DOI:10.1016/j.engfailanal.2020.104953.

Boral, S., Howard, I., Chaturvedi, S.K., McKee, K. \& Naikan, V.N.A. (2020a). An integrated approach for fuzzy failure modes and effects analysis using fuzzy AHP and fuzzy MAIRCA. Engineering Failure Analysis, 108, 16. DOI:10.1016/j.engfailanal.2019.104195.

Fang, H., Li, J. \& Song, W.Y. (2020). Failure mode and effects analysis: an integrated approach based on rough set theory and prospect theory. Soft Computing, 24(9), 6673-6685. DOI:10.1007/s00500-019-04305-8.

Hu, L.H., Kang, R., Pan, X. \& Zuo, D.J. (2020a). Risk assessment of uncertain random system-Level-1 and level-2 joint propagation of uncertainty and probability in fault tree analysis. Reliability Engineering \& System Safety, 198, 10. DOI:10.1016/j.ress.2020.106874.

Purba, J.H., Tjahyani, D.T.S., Widodo, S. \& Ekariansyah, A.S. (2020). Fuzzy probability based event tree analysis for calculating core damage frequency in nuclear power plant probabilistic safety assessment. Progress in Nuclear Energy, 125, 9. DOI:10.1016/j.pnucene.2020.103376. Marhavilas, P.K., Filippidis, M., Koulinas, G.K. \& Koulouriotis, D.E. (2020). An expanded HAZOP-study with fuzzy-AHP (XPA-HAZOP technique): Application in a sour crude-oil processing plant. Safety Science, 124, 14. DOI:10.1016/j.ssci.2019.104590.

Velasquez, R.M.A. (2020). Root cause analysis for inverters in solar photo-voltaic plants. Engineering Failure Analysis, $118,18$. DOI:10.1016/j.engfailanal.2020.104856.

Li, J., Fang, H. \& Song, W. (2019a). Failure Mode and Effects Analysis Using Variable Precision Rough Set Theory and TODIM Method. IEEE Transactions on Reliability, 68(4), 1242-1256. DOI:10.1109/tr.2019.2927654.

Lo, H.-W., Liou, J.J.H., Huang, C.-N. \& Chuang, Y.-C. (2019). A novel failure mode and effect analysis model for machine tool risk analysis. Reliability Engineering \& System Safety, 183, 173-183. DOI:10.1016/j.ress.2018.11.018.

Liu, H.-C., Hu, Y.-P., Wang, J.-J. \& Sun, M. (2019a). Failure Mode and Effects Analysis Using Two-Dimensional Uncertain Linguistic Variables and Alternative Queuing Method. IEEE Transactions on Reliability, 68(2), 554-565. DOI:10.1109/tr.2018.2866029.

Chang, C.H., Kontovas, C., Yu, Q. \& Yang, Z.L. (2021). Risk assessment of the operations of maritime autonomous surface ships. Reliability Engineering \& System Safety, 207, 11. DOI:10.1016/j.ress.2020.107324.

Deulgaonkar, V.R., Ingolikar, N., Borkar, A., Ghute, S. \& Awate, N. (2021). Failure analysis of diesel engine piston in transport utility vehicles. Engineering Failure Analysis, 120, 10. DOI:10.1016/j.engfailanal.2020.105008.

Dadsena, K.K., Sarmah, S.P. \& Naikan, V.N.A. (2019). Risk evaluation and mitigation of sustainable road freight transport operation: a case of trucking industry. International Journal of Production Research, 57(19), 6223-6245. DOI:10.1080/00207543.2019.1578429.

Rezaee, M.J., Yousefi, S., Valipour, M. \& Dehdar, M.M. (2018). Risk analysis of sequential processes in food industry integrating multi-stage fuzzy cognitive map and process failure mode and effects analysis. Computers \& Industrial Engineering, 123, $325-337$. DOI:10.1016/j.cie.2018.07.012.

Zheng, H. \& Tang, Y. (2020). A Novel Failure Mode and Effects Analysis Model Using Triangular Distribution-Based Basic Probability Assignment in the Evidence Theory. IEEE Access, 8, 66813-66827. DOI:10.1109/access.2020.2986807.

Boral, S., Howard, I., Chaturvedi, S.K., McKee, K. \& Naikan, V.N.A. (2020b). A novel hybrid multi-criteria group decision making approach for failure mode and effect analysis: An essential requirement for sustainable manufacturing. Sustainable Production And Consumption, 21, 14-32. DOI:10.1016/j.spc.2019.10.005.

Xu, Y., Shang, X.P., Wang, J., Zhang, R.T., Li, W.Z. \& Xing, Y.P. (2019). A method to multi-attribute decision making with picture fuzzy information based on Muirhead mean. Journal Of Intelligent \& Fuzzy Systems, 36(4), 3833-3849. DOI:10.3233/jifs-172130.

Luo, S.Z., Liang, W.Z. \& Zhao, G.Y. (2020). Likelihood-based hybrid ORESTE method for evaluating the thermal comfort in underground mines. Applied Soft Computing, 87. DOI:10.1016/j.asoc.2019.105983.

Ju, Y.B., Ju, D.W., Gonzalez, E., Giannakis, M. \& Wang, A.H. (2019). Study of site selection of electric vehicle charging station based on extended GRP method under picture fuzzy environment. Computers \& Industrial Engineering, 135, 1271-1285. DOI:10.1016/j.cie.2018.07.048. 
Li, X., Ju, Y.B., Ju, D.W., Zhang, W.K., Dong, P.W. \& Wang, A.H. (2019b). Multi-Attribute Group Decision Making Method Based on EDAS Under Picture Fuzzy Environment. IEEE Access, 7, 141179-141192. DOI:10.1109/access.2019.2943348.

Wang, L., Zhang, H.Y., Wang, J.Q. \& Li, L. (2018a). Picture fuzzy normalized projection-based VIKOR method for the risk evaluation of construction project. Applied Soft Computing, 64, 216-226. DOI:10.1016/j.asoc.2017.12.014.

Zhang, P.W., Tao, Z.F., Liu, J.P., Jin, F.F. \& Zhang, J.T. (2020). An ELECTRE TRI-based outranking approach for multi-attribute group decision making with picture fuzzy sets. Journal Of Intelligent \& Fuzzy Systems, 38(4), 4855-4868. DOI:10.3233/jifs-191540.

Zeng, S., Asharf, S., Arif, M. \& Abdullah, S. (2019). Application of Exponential Jensen Picture Fuzzy Divergence Measure in Multi-Criteria Group Decision Making. Mathematics, 7(2), 191. DOI:10.3390/math7020191.

Singh, P., Mishra, N.K., Kumar, M., Saxena, S. \& Singh, V. (2018). Risk analysis of flood disaster based on similarity measures in picture fuzzy environment. Afrika Matematika, 29(7-8), 1019-1038. DOI:10.1007/s13370-018-0597-x.

Van Dinh, N. \& Xuan Thao, N. (2018). Some Measures of Picture Fuzzy Sets and Their Application in Multi-attribute Decision Making. International Journal of Mathematical Sciences and Computing, 4(3), 23-41. DOI:10.5815/ijmsc.2018.03.03.

Wei, G. \& Gao, H. (2018). The Generalized Dice Similarity Measures for Picture Fuzzy Sets and Their Applications. Informatica, 29(1), 107124. DOI:10.15388/Informatica.2018.160.

Dutta, P. (2018). Medical Diagnosis Based on Distance Measures Between Picture Fuzzy Sets. International Journal of Fuzzy System Applications, 7, 15-36. DOI:10.4018/IJFSA.2018100102.

Son, L.H. (2017). Measuring analogousness in picture fuzzy sets: from picture distance measures to picture association measures. Fuzzy Optimization and Decision Making, 16(3), 359-378. DOI:10.1007/s10700-016-9249-5.

Khan, M.J., Kumam, P., Deebani, W., Kumam, W. \& Shah, Z. (2020). Bi-parametric distance and similarity measures of picture fuzzy sets and their applications in medical diagnosis. Egyptian Informatics Journal. DOI:10.1016/j.eij.2020.08.002.

Ganie, A.H. \& Singh, S. An innovative picture fuzzy distance measure and novel multi-attribute decision-making method. Complex \& Intelligent Systems, 25. DOI:10.1007/s40747-020-00235-3.

Liu, M.L., Zeng, S.Z., Balezentis, T. \& Streimikiene, D. (2019b). PICTURE FUZZY WEIGHTED DISTANCE MEASURES AND THEIR APPLICATION TO INVESTMENT SELECTION. Amfiteatru Economic, 21(52), 682-695. DOI:10.24818/ea/2019/52/682.

Duong, T.T.T. \& Thao, N.X. (2021). 1 A novel dissimilarity measure on picture fuzzy sets and its application in multi-criteria decision making. Soft Computing, 25(1), 15-25. DOI:10.1007/s00500-020-05405-6.

Wang, W.Z., Liu, X.W., Qin, Y. \& Fu, Y. (2018b). A risk evaluation and prioritization method for FMEA with prospect theory and Choquet integral. Safety Science, 110, 152-163. DOI:10.1016/j.ssci.2018.08.009.

Gul, M., Yucesan, M. \& Celik, E. (2020). A manufacturing failure mode and effect analysis based on fuzzy and probabilistic risk analysis. Applied Soft Computing, 96, 12. DOI:10.1016/j.asoc.2020.106689.

Mohsen, O. \& Fereshteh, N. (2017). An extended VIKOR method based on entropy measure for the failure modes risk assessment - A case study of the geothermal power plant (GPP). Safety Science, 92, 160-172. DOI:10.1016/j.ssci.2016.10.006.

Zhang, H.J., Dong, Y.C., Palomares-Carrascosa, I. \& Zhou, H.W. (2019). Failure Mode and Effect Analysis in a Linguistic Context: A Consensus-Based Multiattribute Group Decision-Making Approach. IEEE Transactions on Reliability, 68(2), 566-582. DOI:10.1109/tr.2018.2869787.

Yi, P.T., Dong, Q.K. \& Li, W.W. (2019). Evaluation of city sustainability using the deviation maximization method. Sustainable Cities and Society, 50, 8. DOI:10.1016/j.scs.2019.101529.

Wu, S.M., You, X.Y., Liu, H.C. \& Wang, L.E. (2020). Improving quality function deployment analysis with the cloud MULTIMOORA method. International Transactions In Operational Research, 27(3), 1600-1621. DOI:10.1111/itor.12484.

Li, Y.L., Wang, R. \& Chin, K.S. (2019c). New failure mode and effect analysis approach considering consensus under interval-valued intuitionistic fuzzy environment. Soft Computing, 23(22), 11611-11626. DOI:10.1007/s00500-018-03706-5.

Luo, S.Z. \& Liang, W.Z. (2019). Optimization of roadway support schemes with likelihood-based MABAC method. Applied Soft Computing, 80, 80-92. DOI:10.1016/j.asoc.2019.03.020.

Nie, R.X., Tian, Z.P., Wang, X.K., Wang, J.Q. \& Wang, T.L. (2018). Risk evaluation by FMEA of supercritical water gasification system using multi-granular linguistic distribution assessment. Knowledge-Based Systems, 162, 185-201. DOI:10.1016/j.knosys.2018.05.030. 
Chen, L.Y. \& Deng, Y. (2018). A new failure mode and effects analysis model using Dempster-Shafer evidence theory and grey relational projection method. Engineering Applications Of Artificial Intelligence, 76, 13-20. DOI:10.1016/j.engappai.2018.08.010.

Zhao, H., You, J.-X. \& Liu, H.-C. (2016). Failure mode and effect analysis using MULTIMOORA method with continuous weighted entropy under interval-valued intuitionistic fuzzy environment. Soft Computing, 21(18), 5355-5367. DOI:10.1007/s00500-016-2118-x.

Hu, Y., Gou, L., Deng, X. \& Jiang, W. (2020b). Failure mode and effect analysis using multi - linguistic terms and Dempster - Shafer evidence theory. Quality And Reliability Engineering International. DOI:10.1002/qre.2773.

Yousefi, S., Alizadeh, A., Hayati, J. \& Baghery, M. (2018). HSE risk prioritization using robust DEA-FMEA approach with undesirable outputs: A study of automotive parts industry in Iran. Safety Science, 102, 144-158. DOI:10.1016/j.ssci.2017.10.015.

Mardani, A., Saraji, M.K., Mishra, A.R. \& Rani, P. (2020). A novel extended approach under hesitant fuzzy sets to design a framework for assessing the key challenges of digital health interventions adoption during the COVID-19 outbreak. Applied Soft Computing, 96, 14. DOI:10.1016/j.asoc.2020.106613.

Pamucar, D., Deveci, M., Canitez, F. \& Lukovac, V. (2020). Selecting an airport ground access mode using novel fuzzy LBWA-WASPAS-H decision making model. Engineering Applications Of Artificial Intelligence, 93, 20. DOI:10.1016/j.engappai.2020.103703.

Tian, C., Peng, J.J., Zhang, S., Zhang, W.Y. \& Wang, J.Q. (2019). Weighted picture fuzzy aggregation operators and their applications to multicriteria decision-making problems. Computers \& Industrial Engineering, 137, 12. DOI:10.1016/j.cie.2019.106037.

Jana, C., Senapati, T., Pal, M. \& Yager, R.R. (2019). Picture fuzzy Dombi aggregation operators: Application to MADM process. Applied Soft Computing, 74, 99-109. DOI:10.1016/j.asoc.2018.10.021.

Wei, G. (2017). Picture fuzzy aggregation operators and their application to multiple attribute decision making. Journal Of Intelligent \& Fuzzy Systems, 33(2), 713-724. DOI:10.3233/jifs-161798.

Chen, Y.F., Ran, Y., Wang, Z.C., Li, X.L., Yang, X. \& Zhang, G.B. (2020). An extended MULTIMOORA method based on OWGA operator and Choquet integral for risk prioritization identification of failure modes. Engineering Applications Of Artificial Intelligence, 91, 12. DOI:10.1016/j.engappai.2020.103605.

Dice, L.R. (1945). MEASURES OF THE AMOUNT OF ECOLOGIC ASSOCIATION BETWEEN SPECIES. Ecology, $26(3), 297-302$. DOI: $10.2307 / 1932409$.

Jaccard, P. (1901). Distribution de la ore alpine dans la Bassin de Dranses et dans quelques regions voisines. Bulletin de la Société Vaudoise des. Sciences Naturelles, 7(140), 241-272. DOI:10.5169/seals-266440.

Liu, H.C., You, J.X. \& Duan, C.Y. (2019c). An integrated approach for failure mode and effect analysis under interval-valued intuitionistic fuzzy environment. International Journal Of Production Economics, 207, 163-172. DOI:10.1016/j.ijpe.2017.03.008.

Aydogdu, A. \& Gul, S. (2020). A novel entropy proposition for spherical fuzzy sets and its application in multiple attribute decision-making. International Journal Of Intelligent Systems, 35(9), 1354-1374. DOI:10.1002/int.22256. 